\title{
Intermediate Inheritance with Disomic Tendency in Tetraploid Intergeneric Citrus $\times$ Poncirus Hybrids Enhances the Efficiency of Citrus Rootstock Breeding
}

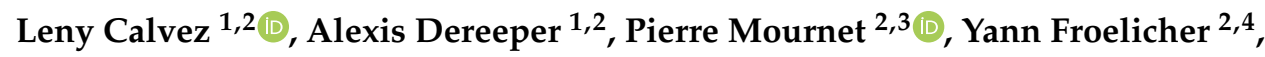 \\ Saturnin Bruyère ${ }^{1,2}$, Raphaël Morillon ${ }^{1,2}$ and Patrick Ollitrault ${ }^{2,4, *}$ \\ 1 CIRAD, UMR AGAP, 97170 Petit-Bourg, France; leny.calvez@cirad.fr (L.C.); alexis.dereeper@cirad.fr (A.D.); \\ saturnin.bruyere@cirad.fr (S.B.); raphael.morillon@cirad.fr (R.M.) \\ 2 AGAP, Institut Agro, University of Montpellier, CIRAD, INRAE, 34060 Montpellier, France; \\ pierre.mournet@cirad.fr (P.M.); yann.froelicher@cirad.fr (Y.F.) \\ 3 CIRAD, UMR AGAP, 34398 Montpellier, France \\ 4 CIRAD, UMR AGAP, 20230 San Giuliano, France \\ * Correspondence: patrick.ollitrault@cirad.fr
}

Received: 5 November 2020; Accepted: 9 December 2020; Published: 13 December 2020

check for updates

\begin{abstract}
Rootstocks are crucial for the sustainability of the citrus industry worldwide. Diploid intergeneric Citrus $\times$ Poncirushybrids have contributed considerably to citrus rootstock improvement and their tetraploid (doubled-diploid) forms are important resources for the creation of a new generation of tetraploid rootstocks. To optimize the efficiency of tetraploid rootstock breeding strategies, more knowledge is required on inheritance in the allotetraploid genitors. A set of 159 new SNP markers that fully distinguish Poncirus trifoliata (L.) Raf. from Citrus species was developed from polymorphisms mined in GBS data and used to establish a genetic map of tetraploid citrumelo $(C . \times$ paradisi Macfad. $\times$ P. trifoliata) and to analyze the meiotic behavior of tetraploid citrumelo and citrandarin (C. reticulata Blanco $\times$ P. trifoliata). The tetraploid citrumelo genetic map was highly syntenic and collinear with the clementine reference genome. The apparent intergeneric recombination rate was strongly limited by high preferential chromosome pairing, resulting in intermediate inheritance with disomic tendency. Such inheritance, also observed in tetraploid citrandarin, results in the transmission by the diploid gametes of a high rate of intergeneric heterozygosity. It is therefore expected that a large part of the genetic value selected in the original diploid intergeneric rootstock is transmitted to the tetraploid sexual progenies.
\end{abstract}

Keywords: polyploidy; meiosis; preferential chromosome pairing; genetic map; single nucleotide polymorphism

\section{Introduction}

Citrus rootstock is a critical component of the modern citrus industry. Grafting has been practiced for centuries, but the great interest in citrus rootstock and the profound transformation of the citrus industry with the generalization of citrus grafting was triggered by the world phytophthora crisis at the end of the 18th century [1]. Sour orange (C. $\times$ aurantium L.) was the most widely used rootstock until the emergence of a second major disease outbreak caused by the citrus tristeza virus (CTV) that killed millions of trees grafted onto sour orange all over the world. This crisis resulted in major diversification of citrus rootstock for better adaptation to the different citrus production regions and a diversity of biotic and abiotic constraint. Indeed, for citrus, the rootstock is the main component in adaptation of the citrus tree to different environments. 
Today, global climate change and environmental instability over seasons and years means we need to increase tolerance to abiotic stresses and improve the resilience of grafted trees [2]. Water deficit and salinity in particular, have become increasingly frequent. Some citrus rootstock, including Rangpur lime, Cleopatra mandarin and Alemow, are well known for their better adaptation to abiotic stresses [3]. Phytophtora, CTV, and nematodes, which are present all over the world, are among the disease and pest problems that can be solved using rootstock. Other diseases may concern only specific production areas, such as the sudden death that affected trees when grafted onto Rangpur lime in Brazil [4]. The genus Poncirus (trifoliate oranges) is a very important genetic resource for the improvement of rootstock for disease resistances, particularly against CTV [5]. However, trifoliate oranges are sensitive to iron chlorosis on alkaline soils as well as to salinity, which limits their use in some areas, particularly in the Mediterranean Basin [6]. Intergeneric hybridization between Citrus and Poncirus species enabled significant progress in rootstock selection using hybrids such as Swingle citrumelo (C. $\times$ paradisi Macfad. $\times$ P. trifoliata (L.) Raf.), Carrizo, Troyer and C 35 citranges $(C . \times$ sinensis (L.) Osbeck $\times$ P. trifoliata) and several citrandarin $(C$. reticulata Blanco $\times$ P. trifoliata). Today, Huanglongbing disease (HLB) caused by three Candidatus Liberibacter species is the main constraint in the citrus industry worldwide. After contamination of citrus leaves by a psyllid, the bacteria progress through the phloem down to the root system where they cause root degradation and severe physiological disorders [7-9]. The selection of rootstock that is tolerant or resistant to HLB is therefore important in the fight against HLB disease. Recently true resistance to HLB was found in Microcitrus and Eremocitrus [10], two Australian citrus genera sexually compatible with cultivated Citrus species and Poncirus trifoliata and may constitute important resources for further citrus rootstock improvement.

In addition to adaptation to abiotic stresses and resistance to citrus diseases, rootstock also drives tree vigor and yield, fruiting earliness and certain quality attributes, particularly in tangerines. Rootstock breeding therefore requires combining a large number of useful traits, however, the cumbersome nature of the evaluation of the different criteria seriously limits the number of hybrids that can be assessed. In these circumstances, breeding strategies are needed that allow a large part of the multi-trait value selected at the parent level to be transmitted to the progeny. Considering the complementarity of breeding traits that can be found in the different species and genera, rootstock breeding programs also usually aim to combine germplasms with important genetic differentiation.

Interestingly, in citrus, polyploidy has been reported to improve adaptation to different types of stress and to promote resilience [11]. Under salinity stress or water deficit, tetraploid seedlings were shown to be more tolerant than their parental diploid counterparts [12-17]. Increased tolerance was also observed when rootstock was grafted [18-20]. Better tolerance to cold was reported in clementine trees grafted onto tetraploid Carrizo citrange [21]. An allotetraploid rootstock (C. reticulata + P. trifoliata) was also shown to be more tolerant to cold and light stress than its two diploid parents [22]. Citrumelo 4475 and Volkamer lemon tetraploid seedlings were less affected by nutritional stress than the corresponding diploid seedlings [23]. The tetraploid Carrizo citrange appears to be less sensitive to boron excess than the corresponding diploid [24]. Transcriptome studies revealed constitutive overexpression of genes involved in stress response in tetraploid citrus compared to their diploid parents $[18,19,25]$.

To take advantage of the improved adaptation to stress by polyploid citrus, several teams have been developing tetraploid rootstock [26-34]. Tetraploid rootstocks resulting from spontaneous chromosome doubling of nucellar cells in apomictic lines have been selected in parental diploid rootstock seedlings [35]. The tetraploid citrumelo 4475, citrandarin and Volkamer lemon used in the present work resulted from such selection by flow cytometry. However, this approach does not allow combining resistance traits from different germplasm resources. Somatic hybridization by protoplast fusion is an efficient tool to cumulate the whole nuclear genome of the two parents, without recombination and to potentially combine the complementary beneficial dominant traits of both parents. Somatic hybridization has been successfully applied in several tetraploid citrus rootstock breeding projects $[29,30,36]$. The advantage of the absence of recombination when adding dominant favorable traits is also the main limitation of this breeding strategy given the existence of unfavorable dominant traits and the absence of variability 
obtained from a couple of parents. The "Tetrazyg" breeding strategy was recently developed to breed new tetraploid rootstock by sexual hybridization using selected somatic hybrid rootstock or doubled diploids as parent material [30].

To optimize the efficiency of the "Tetrazyg" strategy, we need to improve our knowledge of the mode of inheritance in the tetraploid hybrids used as parents. Indeed, much diploid citrus rootstock results from ancient natural interspecific hybridization (i.e., sour orange $=$ C. maxima $($ Burm.) Merr $\times$ C. reticulata; Volkamer lemon and Rangpur lime $=$ C. reticulata $\times$ C. medica L.; Alemow $=$ C. micrantha Wester $\times$ C. medica; [37-40]) or inter-generic hybridization (Citrus $\times$ Poncirus) performed in citrus breeding programs (Figure 1$)$. Citrumelo $(C . \times$ paradisi $\times$ P. trifoliata) display the most complex genomic structure with the contribution of three ancestral taxa because $C . \times$ paradisi results itself from admixture between C. reticulata and C. maxima ancestral species [38].

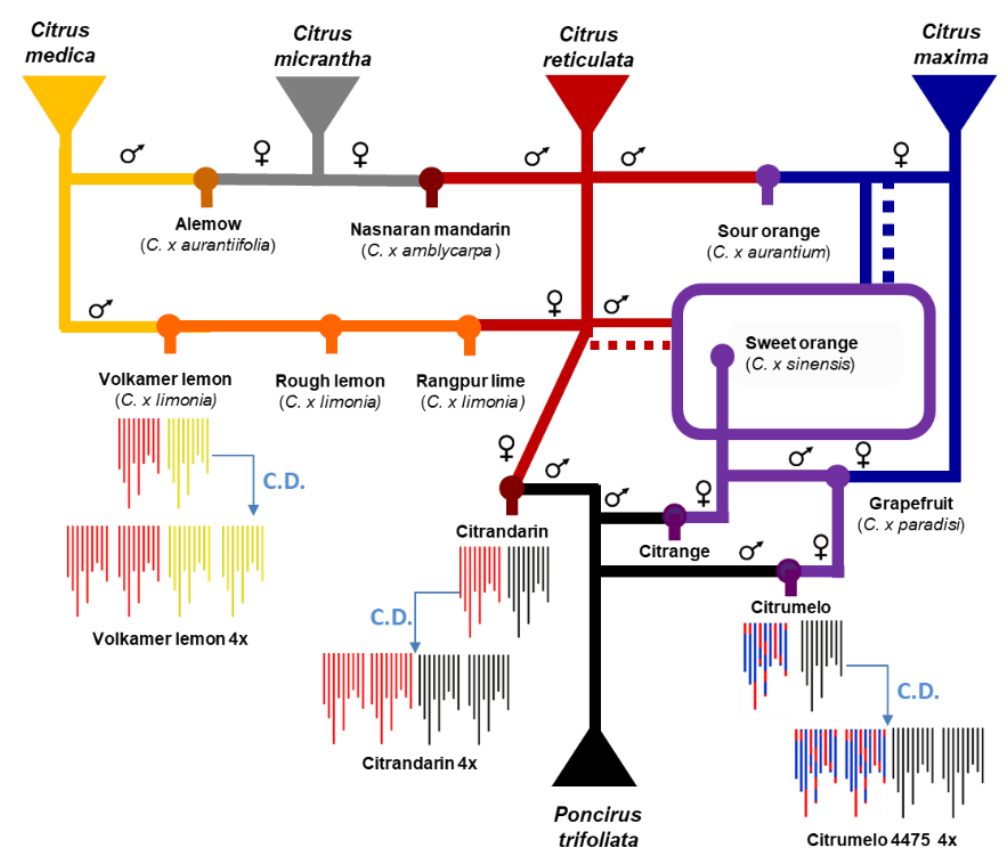

Figure 1. Phylogenetic origin of important interspecific citrus rootstocks and phylogenomic structure of the three tetraploid parents used in this paper. CD: Chromosome doubling of nucellar cells. Ancestral genome contribution: Yellow: C. medica; grey: C. micrantha; Red: C. reticulata; Blue: C. maxima; Black: P. trifoliata.

Doubled diploid lines developed from these rootstocks can be therefore considered as allotetraploids resulting from the merger of the genomes of two divergent species. Allotetraploids typically have strict preferential chromosome pairing in meiosis, resulting in disomic inheritance, with no interspecific recombination, producing diploid gametes with interspecific heterozygosity throughout the genome [41]. However, non-homologous chromosome pairing occasionally occurs in allopolyploids, leading to non-strict disomic inheritance and inter-genomic recombination [42-47]. Therefore, chromosome-pairing affinity is a key parameter in designing efficient polyploid breeding strategies, as it has major impacts on the inheritance of chromosome fragments and agronomical traits. Molecular marker analysis is a powerful tool to estimate preferential pairing pattern along the genome as well as its impacts on genome fragment inheritance and recombination [48-52]. The inference of diploid gamete structure from progeny analysis requires genotyping methods that identify the allelic doses in the polyploid hybrids. Cuenca et al. [53] demonstrated the efficiency of the KASPar single-nucleotide polymorphism (SNP) genotyping technique in assigning heterozygous allelic configurations within polyploid citrus populations and the method was successfully used to analyze the genetic structure and origin of $2 \mathrm{n}$ gametes [53-56] and to perform tetraploid meiosis analyses [46,47,57,58]. 
The aim of the present study was to investigate the mode of inheritance in two doubled-diploid intergeneric Citrus $\times$ Poncirus hybrids selected in seedlings of the 4475 citrumelo $(C . \times$ paradisi $\times$ P. trifoliata) and citrandarin (C. reticulata $\mathrm{cv}$ 'Cleopatra' $\times$ P. trifoliata) rootstocks. The diploid 4475 citrumelo rootstock is used worldwide, and in addition to providing resistance to CTV and phytophthora, it ensures adaptation to different types of soils and climates [59,60]. Citrandarin is also resistant to CTV and Phytophthora spp. and presents interesting behavior against salt stress (our unpublished data). Two tetraploid populations were established using the intergeneric hybrids as pollinators and a tetraploid Volkamer lemon as female parent. With a specific focus on intergeneric recombination and heterozygosity restitution, we developed 188 new Kaspar SNP markers to diagnose Citrus/Poncirus differentiation (marker fixed for one allele in all Citrus species and another allele in Poncirus trifoliata) with good distribution throughout the genome. These diagnostic SNPs (DSNPs) were mined from genotyping by sequencing (GBS) data of representative accessions of the two genera and some intergeneric hybrids. Kaspar markers were then validated in an extended diversity panel and used to genotype the hybrid tetraploid progeny. A genetic map was established for the tetraploid 4475 citrumelo and the intergeneric recombination was analyzed. Preferential pairing was analyzed using the maximum likelihood method proposed by Aleza et al. [57] for doubled diploids. The implications of the meiotic behavior of Citrus $\times$ Poncirus intergeneric hybrids for citrus rootstock breeding are discussed.

\section{Materials and Methods}

\subsection{Plant Material}

Germplasm: the discovery panel used for the GBS analysis to identify DSNPs of Poncirus trifoliata included 31 diploid accessions: five varieties representative of $C$. medica, C. reticulata and C. maxima, one C. micrantha, six Citrus secondary species, four representatives of $P$. trifoliata and five intergeneric hybrids (Table S1). Fifty-four accessions were genotyped to validate the Kaspar markers: 13 trifoliate orange, 11 Citrus, 25 intergeneric hybrids and five related genera of the Aurantioideae subfamily. All these varieties came from the collection belonging to the Inrae-Cirad Citrus Biological Resource Center in San-Giuliano (Corsica, France).

Tetraploid Intergeneric progenies: two tetraploid segregating progenies were established to analyze the meiotic behavior of 4475 citrumelo (SRA 1112) and Cleopatra mandarin $\times$ Poncirus trifoliata citrandarin (SRA 1114) tetraploid intergeneric hybrids and to construct the genetic map of tetraploid 4475 citrumelo. A tetraploid Volkamer lemon accession (SRA 1122) was hand pollinated with pollen from the two intergeneric hybrids. The three tetraploid parents were selected several years ago in Corsica, in seedlings of their corresponding diploid rootstock and belong to the Inrae-Cirad Citrus Biological Resource Center. Molecular marker analysis demonstrated that these three tetraploid rootstocks are doubled-diploid lines. The seeds obtained from the hand pollinated flowers were sown in a greenhouse. Considering the facultative apomixes of Volkamer lemon, all recovered plantlets were analyzed with SNP markers to identify the zygotic seedlings. Respectively 125 and 58 hybrids were selected for Volkamer lemon $\times$ citrumelo and Volkamer lemon $\times$ citrandarin hybridization. The tetraploid status of these 183 plantlets was confirmed by flow cytometry analysis of young leaves according to the method described by Dambier et al. [29].

\subsection{GBS Analysis}

To identify polymorphisms that fully differentiate trifoliate orange from Citrus species, we combined GBS data previously published in Oueslati et al. [61] and Ahmed et al. [40] for Citrus species with newly generated data for trifoliate orange and intergeneric hybrids (Table S1).

Following the protocol of Oueslati et al. [61], genomic DNA was isolated using the Plant DNAeasy ${ }^{\circledR}$ kit (Qiagen, Hilden, Germany), according to the manufacturer's instructions. The concentration of genomic DNA was adjusted to $20 \mathrm{ng} / \mu \mathrm{L}$, and ApeKI GBS libraries were prepared following the protocol described by Elshire et al. [62]. DNA of each sample (200 ng) was first digested with the ApeKI enzyme (New England Biolabs, Hitchin, UK) at $75^{\circ} \mathrm{C}$ for $2 \mathrm{~h}$ and then at $65^{\circ} \mathrm{C}$ for $20 \mathrm{~min}$ to inactivate the 
enzyme. The ligation reaction was completed in the same plate as digestion, again using T4 DNA ligase enzyme (New England Biolabs) at $22^{\circ} \mathrm{C}$ for $1 \mathrm{~h}$ and the ligase was inactivated prior to pooling of the samples by holding the temperature at $65{ }^{\circ} \mathrm{C}$ for $20 \mathrm{~min}$. Ligated samples were pooled and PCR-amplified in a single tube. Complexity was further reduced by using PCR primers with one selective base (A) as performed by Sonah et al. [63]. Analyzed data came from single-end sequencing performed with Illumina HiSeq2000 or Illumina HiSeq4000 (Illumina, San Diego, CA, USA) depending in the accessions (Table S1).

Genotype calling was performed as described in Ahmed et al. [40]. The Tassel 4.0 pipeline [64] was used to call SNPs from the DNA sequence reads from the raw Illumina data (unfiltered fastq file). The Tassel 4.0 GBS pipeline identified good quality, unique sequence reads with barcodes. These sequence tags were aligned with the C. clementina 1.0 reference genome (https://phytozome.jgi.doe.gov/) using Bowtie2 v 2.2.6 [65]. For genotype calling, five reads were considered as a minimum below which they were considered as missing data [66]. We only considered diallelic polymorphic positions with less than $15 \%$ of missing data for the 31 accessions and a minor allele frequency (MAF) $>0.05$. The Illumina Hiseq 2000 raw data used for sequencing are available in the NCBI SRA (Sequence Read Archive), under accession numbers SRP109295 for the mandarin, pummelo, orange, grapefruit accessions already published in Oueslati et al. [61], PRJNA388540 for the citron, micrantha, lemons and limes accessions previously genotyped by Ahmed et al. [40] and PRJNA648274 for the accessions of Poncirus and intergeneric hybrids newly genotyped for the present study (Table S1). Keygene N.V. (Keygene, Wageningen, Netherlands) owns the patents and patent applications protecting its Sequence Based Genotyping technologies.

\subsection{Diversity and Genetic Relationship Analysis Based on GBS Data}

The search for diagnostic SNPs of Citrus and Poncirus differentiation was based on the estimation of the inter-population differentiation parameter $\left(G_{S T}\right)$ defined by Nei [67]. $G_{S T}$ was computed using the estimated allele frequency of each taxon while considering the same population size for each taxon to estimate the frequency of the whole population $(T o t)$ :

$$
G_{S T}=\left(H e_{T o t}-\left(H e_{\text {reticulata }}+H e_{\text {maxima }}\right) / 2\right) / H e_{\text {Tot }}
$$

where $H e$ is the expected proportion of heterozygous loci per individual $\left(H e=1-\Sigma \mathrm{pi}^{2}\right.$, pi is the frequency of a given allele in the population or subpopulation considered). $\mathrm{He}_{T o t}$ refer to the whole population; $\mathrm{He}_{\text {reticulata }}$ to the representative accessions of $\mathrm{C}$. reticulata and $\mathrm{He}_{\text {maxima }}$ to the representative accessions of $C$. maxima. $G_{S T}$ values ranged from zero to one. $G_{S T}=1$ means that the two taxa were fully differentiated and was the criterion for DSNP identification. Observed heterozygosity $(\mathrm{Ho})$, expected heterozygosity $(\mathrm{He})$ and $G_{S T}$ estimations were computed with Microsoft Excel 2016 (Microsoft Corp, Redmond, WA, USA). Neighbor-joining analysis and factorial analysis were computed using DARwin software version 6.0 [68]. Both were based on the Manhattan index:

$$
D_{i-j}=1 / K \sum_{1}^{K}\left|x_{i k}-x_{j k}\right|
$$

where $i$ and $j$ are the two considered individuals, $k$ the considered locus, $K$ the total number of loci and $x_{i k}$ the frequency of the alternative allele at locus $k$ for the individual $i$.

For GBS data analysis, the weighted neighbor-joining tree was computed from the dissimilarity matrix, including only the accession representative of the Citrus and Poncirus genera. All accessions, including intergeneric hybrids, were used for the factorial analysis.

\subsection{Development of P. trifoliata DSNPs Kaspar Markers and Population Genotyping}

Genetic analysis of polyploid populations requires unambiguous estimation of allele doses for heterozygous genotypes. GBS analysis of polyploid citrus revealed the difficulty involved in inferring 
allele doses at individual SNP polymorphisms [40]. We therefore chose the KASPar SNP genotyping method that allows clear identification of the doses of alleles in polyploid hybrids [53] to answer the research questions we tackled in this paper. To study the meiosis of the tetraploid intergeneric parents, we identified Poncirus DSNPs with a PP, CC and PC configuration, respectively, for all the trifoliate orange, Citrus species, and intergeneric hybrids we analyzed. Among them, we selected 188 DSNPs that provide good coverage of the nine citrus chromosomes and are located more than 50 bases from the next identified polymorphism. Four previously developed P. trifoliata DSNPs [69] were added to genotype the 183 tetraploid intergeneric hybrids, their three parents, and the 51 germplasm accessions used for marker validation. Information on the selected SNP markers is provided in Table S2. LGC Genomics (Middlesex, UK; www.lgcgenomics.com) performed KASPar genotyping. The KASPar ${ }^{\mathrm{TM}}$ genotyping system is a competitive, allele-specific dual Förster Resonance Energy Transfer (FRET)-based assay. LGC Genomics extracted the DNA from the leaf samples, designed the primers based on the SNP locus-flanking sequences and performed the genotyping. Details on the KASPar method are provided in [70]. The allele doses of the tetraploid hybrids and parents were estimated from their respective allele signals based on the method described by Cuenca et al. [53] using KlusterCaller software V3.4.1.36 (LGC Genomics) with manual identification of PCCC and PPCC heterozygous clusters. An illustration is given in Figure 2 with the identification of three clusters (PPCC; PCCC and CCCC) for the tetraploid hybrids (N.B. the two PP individuals are Poncirus controls). For each hybrid, two doses of $C$ came from the tetraploid Volkamer lemon gamete; the genotype of the diploid gamete was therefore directly inferred from the tetraploid hybrid one: PP, PC and CC for the PPCC, PCCC, and CCCC hybrids respectively).

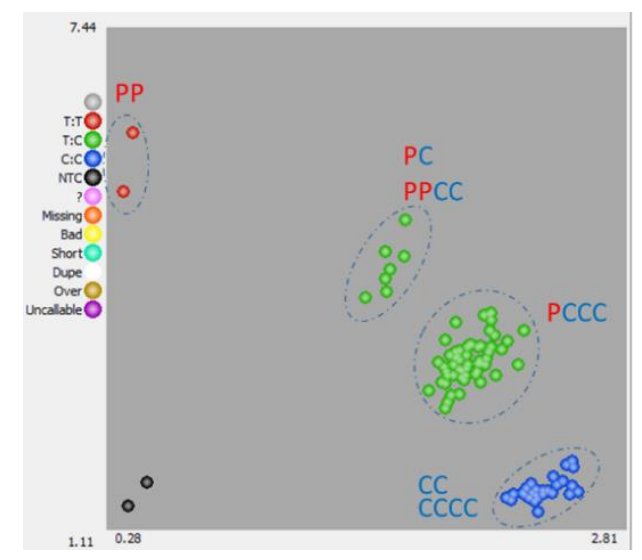

Figure 2. Example of allelic doses estimated with KASPar marker (P3_5432785) on the Volkamer lemon $\times$ Citrumelo population. P: Poncirus allele; C: Citrus allele.

\subsection{Intergeneric Recombination and Mapping Analysis of Tetraploid Citrumelo 4475}

The genetic map of the tetraploid citrumelo was built using the \{pergola\} R package [71]. Genotyping data were filtered to less than $20 \%$ of missing data for markers and hybrids. The map was created using the multidimensional scaling algorithm and the Kosambi mapping function that allows incomplete interference among the recombination events. The graphical representation of the genetic map using the resulting ordered and spaced markers was generated by the MapChart program [72]. To evaluate collinearity between the genetic and physical positions of the markers (clementine reference genome [37]) a Marey map plot was performed using Microsoft Excel 2016.

\subsection{Estimation of Preferential Pairing (PP)}

PP defines the proportion of gametes resulting from exclusive pairing of homologous chromosomes and ranges between 0 (full tetrasomic inheritance characteristic of autotetraploids) and 1 (full disomic inheritance in strict allotetraploids). 
For a doubled diploid, under intermediate inheritance, marker segregation depends directly on the rates of chromosome preferential pairing (PP) and double reduction for the marker considered [57]. In the absence of recombination in the centromeric area and hence a null value for double reduction, there is a direct relationship between PP and the parental heterozygosity restitution (PHR) for the centromeric markers [57]. For each chromosome, PP values were estimated for four centromeric and peri-centromeric markers using the maximum likelihood approach proposed for centromeric loci by Aleza et al. [57], and the average value was retained. For each locus the estimation of PP was performed as follows:

Considering the tetrasomic parameter $(\tau=1-\mathrm{PP})$ that defines the proportion of gametes resulting from random meiotic chromosomal pairing used in several previous studies of meiotic behavior of tetraploid citrus $[44,46,47,57,58,73]$ the probability of the three possible diploid gametes produced for a A1A1A2A2 duplex marker can be calculated using the following formulae:

$$
\begin{gathered}
\mathrm{P}\left(\mathrm{A}_{1} \mathrm{~A}_{1}\right)=\tau / 6 \\
\mathrm{P}\left(\mathrm{A}_{2} \mathrm{~A}_{2}\right)=\tau / 6 \\
\mathrm{P}\left(\mathrm{A}_{1} \mathrm{~A}_{2}\right)=1-\tau / 3
\end{gathered}
$$

and the probability to obtain the observed gamete population as a function of $\tau$ is:

$$
\mathrm{L}(\tau)=\mathrm{C} \times\left(\mathrm{P}\left(\mathrm{A}_{1} \mathrm{~A}_{1}\right)^{\mathrm{x} 1}\right) \times\left(\mathrm{P}\left(\mathrm{A}_{2} \mathrm{~A}_{2}\right)^{\mathrm{x} 2}\right) \times\left(\mathrm{P}\left(\mathrm{A}_{1} \mathrm{~A}_{2}\right)^{\mathrm{x} 3}\right)=\mathrm{C} \times(1 / 6 \tau)^{\mathrm{x} 1+\times 2} \times(1-1 / 3 \tau)^{\mathrm{x} 3}
$$

where $C$ is a combinatory coefficient constant for the observed data and $x 1, x 2$ and $x 3$ are respectively the number of observed $A_{1} A_{1}, A_{2} A_{2}$ and $A_{1} A_{2}$ gametes. To estimate $\tau$ by a maximum likelihood approach, for each marker we analyzed the $L(\tau)$ functions with $\tau$ value varying from 0 to 1 with a 0.005 interval. The estimated $\tau$ value was the one maximizing $L(\tau)$. PP was then calculated as $1-\tau$.

Statistical analysis for PP and PHR were conducted in R using the R Studio V3.5.3 environment (R Studio Team, 2016, R Core Team, 2018, Vienna, Austria). The normal distributions of PHR and PP were tested using a QQplot and a Shapiro-Wilk test. It was rejected for PHR ( $p$-value $<0.05)$ but confirmed for PP. Therefore, analyses of variance (ANOVA) were performed to determine significant PP differences between chromosomes and means comparisons were made using a Newman-Keuls test. To study significant PHR differences between chromosomes, a non-parametric Kruskal-Wallis test was used followed by a Wilcoxon test.

\section{Results}

\subsection{Poncirus DSNP Mining from GBS Data}

With the objective to develop SNP markers with the KASPar technology, we focused the variant calling on diallelic SNPs. The tassel pipeline delivered 155,443 diallelic SNPs with genotyping data for at least $50 \%$ of the accessions. After filtering for less than $15 \%$ missing data, we obtained 58,866 diallelic SNPs that were used for further diversity and P. trifoliata dSNP searches. The complete genotyping file for the 58,866 SNPs and the results of diversity parameter analysis chromosome by chromosome and for the whole genome are available in Table S3 and Table 1, respectively.

P. trifoliata displays relatively low diversity $(H e=0.049)$ compared to $\mathrm{C}$. maxima and C. reticulata ( 0.070 and 0.062 , respectively). Considering that its average observed heterozygosity level $(\mathrm{Ho}=0.083)$ is similar to those of these two citrus species, the lower diversity of $P$. trifoliata was mainly associated with low inter-accession diversity, as confirmed by the limited dispersion observed in the $\mathrm{Nj}$ tree analysis (Figure 3A).

The estimated average value of the differentiation parameter $\left(G_{S T}\right)$ between Citrus and Poncirus was 0.261 , with very little variation between chromosomes (Table 1). Among the five Citrus ancestral taxa and P. trifoliata, the latter was the most differentiated from all the others, as clearly shown by NJ tree 
analysis (Figure 3A) and factorial analysis (Figure 3B) with a first axis (44.5\% of total diversity) opposing the genera Citrus and Poncirus, with the intergeneric hybrids in intermediate positions. The analysis of $G_{S T}$ distribution revealed an isolated peak for $G_{S T}=1$ that accounted for 7882 DSNPs of Poncirus (Figure 3C). The number of DSNPs varied between 642 and 1441 on chromosome 7 and chromosome 3 , respectively, in relation with chromosome size. In agreement with the marked differentiation of Poncirus with the Citrus species, the number of P. trifoliata DSNPs is much higher than for C. medica, C. micrantha, C. reticulata and C. maxima (respectively 4737; 3454; 2441 and 1399; Figure 3A).

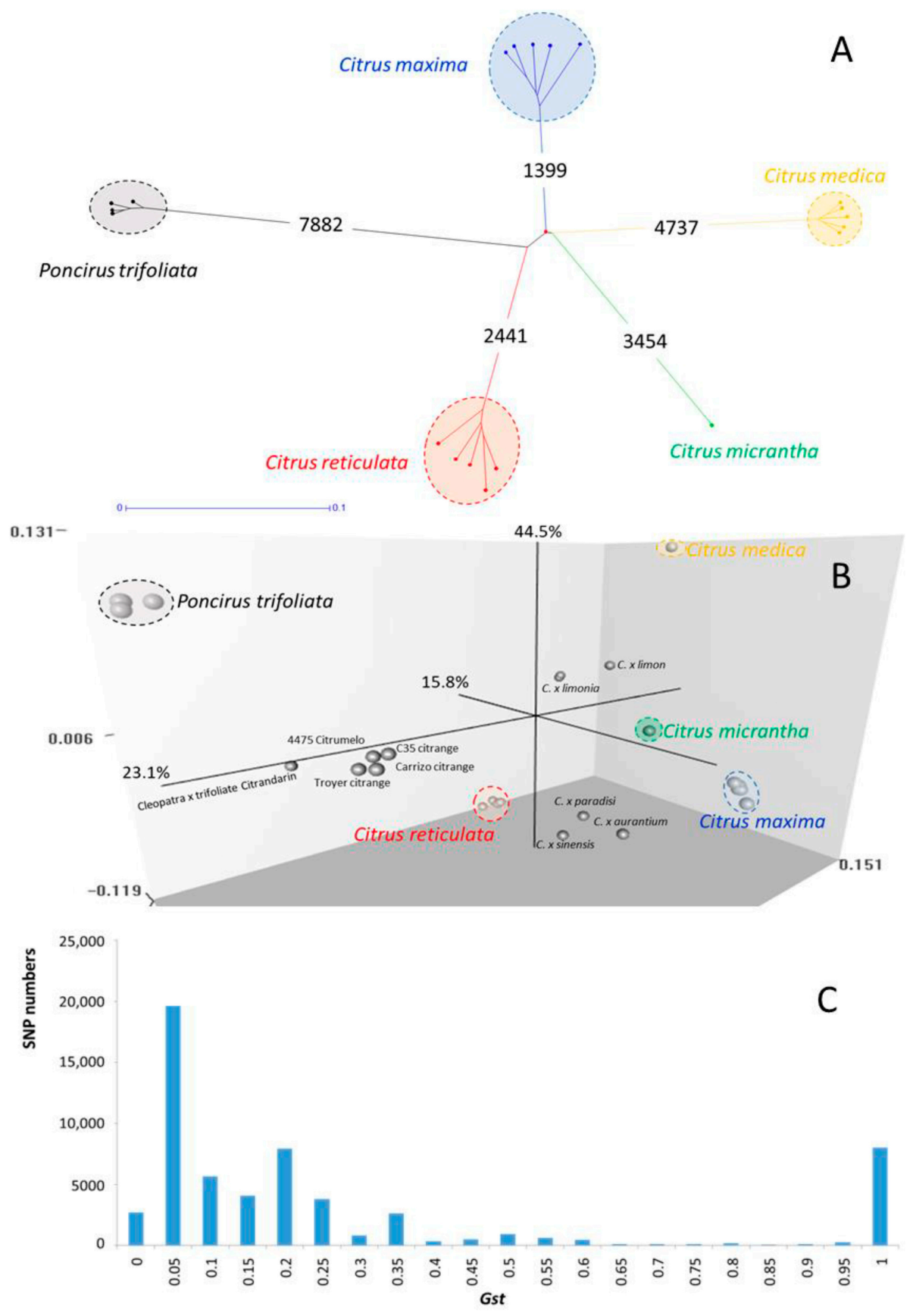

Figure 3. Organization of the genetic diversity revealed by GBS data. (A) Differentiation between ancestor representatives. The number on the branches indicate the numbers of DSNPs for the different taxa. (B) Factorial analysis of the dissimilarity matrix with all accessions. (C) Distribution of $G_{S T}$ values considering Poncirus and Citrus genera as two populations. 
Table 1. Diversity of the Citrus and Poncirus ancestral taxa.

\begin{tabular}{|c|c|c|c|c|c|c|c|c|c|c|c|}
\hline & & Chr1 & Chr2 & Chr3 & Chr4 & Chr5 & Chr6 & Chr7 & Chr8 & Chr9 & Total \\
\hline \multirow{2}{*}{ C. medica } & $\mathrm{He}$ & 0.035 & 0.035 & 0.038 & 0.036 & 0.042 & 0.033 & 0.031 & 0.035 & 0.036 & 0.036 \\
\hline & Ho & 0.038 & 0.035 & 0.039 & 0.034 & 0.049 & 0.035 & 0.035 & 0.039 & 0.046 & 0.039 \\
\hline \multirow{2}{*}{ C. reticulata } & $\mathrm{He}$ & 0.055 & 0.072 & 0.060 & 0.067 & 0.061 & 0.047 & 0.054 & 0.077 & 0.061 & 0.062 \\
\hline & Ho & 0.071 & 0.083 & 0.076 & 0.078 & 0.074 & 0.057 & 0.065 & 0.083 & 0.070 & 0.074 \\
\hline \multirow{2}{*}{ C. maxima } & $\mathrm{He}$ & 0.072 & 0.068 & 0.069 & 0.060 & 0.073 & 0.067 & 0.069 & 0.078 & 0.078 & 0.070 \\
\hline & Ho & 0.090 & 0.084 & 0.088 & 0.075 & 0.096 & 0.085 & 0.083 & 0.097 & 0.088 & 0.087 \\
\hline \multirow{2}{*}{ C. micrantha } & $\mathrm{He}$ & 0.049 & 0.046 & 0.048 & 0.043 & 0.057 & 0.046 & 0.051 & 0.045 & 0.050 & 0.049 \\
\hline & Ho & 0.099 & 0.092 & 0.096 & 0.087 & 0.115 & 0.093 & 0.101 & 0.090 & 0.100 & 0.097 \\
\hline \multirow{2}{*}{ Citrus secondary species } & $\mathrm{He}$ & 0.175 & 0.184 & 0.185 & 0.183 & 0.185 & 0.189 & 0.184 & 0.180 & 0.186 & 0.183 \\
\hline & Ho & 0.243 & 0.226 & 0.248 & 0.246 & 0.241 & 0.268 & 0.258 & 0.243 & 0.250 & 0.246 \\
\hline \multirow{2}{*}{ P. trifoliata } & $\mathrm{He}$ & 0.048 & 0.050 & 0.047 & 0.047 & 0.057 & 0.044 & 0.050 & 0.046 & 0.048 & 0.049 \\
\hline & Ho & 0.081 & 0.086 & 0.082 & 0.077 & 0.099 & 0.072 & 0.082 & 0.080 & 0.085 & 0.083 \\
\hline \multirow{2}{*}{ Inter-generic hybrids } & $\mathrm{He}$ & 0.196 & 0.195 & 0.200 & 0.195 & 0.195 & 0.203 & 0.196 & 0.196 & 0.202 & 0.197 \\
\hline & Ho & 0.319 & 0.304 & 0.307 & 0.312 & 0.298 & 0.314 & 0.300 & 0.302 & 0.314 & 0.308 \\
\hline \multicolumn{2}{|c|}{ Gst Poncirus/Citrus } & 0.268 & 0.259 & 0.266 & 0.262 & 0.250 & 0.273 & 0.247 & 0.260 & 0.261 & 0.261 \\
\hline \multicolumn{2}{|c|}{ Number $P$. trifoliata dSNPs } & 902 & 1006 & 1441 & 860 & 868 & 703 & 642 & 658 & 802 & 7882 \\
\hline
\end{tabular}

Chr: Chromosome, $H o$ : observed heterozygosity, $H e$ : expected heterozygosity (Nei diversity index). G $G_{S T}$ differentiation Index.

\subsection{Development and Validation of Kaspar Markers}

Among the 7882 P. trifoliata DSNPs, we selected 188 SNPs located on genes with no identified additional SNPs at less than 50 bases, and well distributed along the nine chromosomes. An additional selection criterion was heterozygosity of the intergeneric hybrids included in the GBS analysis. Four previously developed P. trifoliata markers [69] were added for the Kaspar analysis. The distribution of the 192 DSNPs on chromosomes 1 to 9 was respectively 20,25, 31, 18, 27, 18, 14, 19 and 20, accounting for the chromosome sizes (Figure S1). The flanking sequences of the DSNPs (50 bases each sides of the DSNPs on the basis of the clementine reference genome) were sent to LGC Genomics to develop the primer sets (Table S2) and to perform SNP genotyping on a panel of 51 diploid germplasm accessions and 183 tetraploid intergeneric hybrids with their three parents.

A total of 159 markers out of the 192 tested had good quality profiles with a high level of transferability (less than $1 \%$ of missing data). For the 33 unsuccessful markers it is possible that close Indel polymorphisms affected the primer affinity or that we missed additional SNPs if the selected DSNP was very close to an ApeKI restriction site.

The frequency of missing data was extremely low in true citrus (Citrus, Poncirus, Fortunella, Microcitrus and Eremocitrus). It increased to $7.5 \%$ in Severinia buxifolia and to $29.6 \%$ in Murraya paniculata, which belong to the Clausenae tribe. While differentiation between Citrus and Poncirus was observed for the 159 markers, for eight of them, we observed some apparent homozygous genotypes among the intergeneric hybrids (Table S4). The marker P4_552023 had the highest rate of missing data particularly in Citrus (five accessions) and homozygous profiles in nine F1 intergeneric hybrids, suggesting the presence of a null allele in homozygosity in some Citrus species and explaining the apparent homozygosity of the intergeneric hybrids. For marker P8_8435664, 11 F1 intergeneric hybrids displayed Poncirus homozygosity, suggesting a null allele in heterozygosity in some Citrus species. Discrepancies in intergeneric hybrids were more specific with six other markers. The citrandarin Cleopatra $\times$ Poncirus displayed apparent Poncirus homozygosity with P3_36705069 and P5_42651578 and apparent Citrus homozygosity with P6_11137084 and P9_30790176. Apparent Poncirus homozygosity was also observed with marker P3_27807440 in Citradia and with marker P5_168354 in Citradia and Citremon. These results strongly suggest the existence of null alleles for these markers. Finally, complete differentiation and full heterozygosity in intergeneric hybrids was observed for 151 markers. In addition, 119 markers fully differentiated Poncirus and related genera. 


\subsection{Genetic Mapping}

A genetic map of the tetraploid citrumelo was built with the population of 125 Volkamer lemon $\times$ citrumelo hybrids. Of the 192 markers analysed, 26 markers failed Kaspar genotyping and seven presented more than $20 \%$ missing data in this family and were thus discarded. Hence, a matrix with 159 makers and 125 individuals was used to build the genetic map. The rate of missing data for this matrix was $2.83 \%$.

The first step in the analysis consisted in analyzing the relationship between markers with a NJ tree analysis based on the Manhattan dissimilarity index between markers using Darwin6 software [68] (Figure S2). The analysis revealed nine main clusters that may correspond to the nine chromosomes of the haploid genome set. Marker-pairwise recombination frequencies were then performed and the ordering and distance between markers were established for each of the nine LGs using the $\mathrm{R}$ package \{pergola\}. The total length of the map is $236.8 \mathrm{cM}$. Linkage groups contained 14 (LG4) to 23 markers (LG3), their size ranging from $13.30 \mathrm{cM}$ for LG4 to $46.17 \mathrm{cM}$ for LG3 (Table 2).

Table 2. Description of the genetic map of the tetraploid 4475 citrumelo and recombination rate.

\begin{tabular}{ccccc}
\hline LG & N.M & L.G. Size (cM) & G. Size $\mathbf{( M b )}$ & RR (cM/Mb) \\
\hline 1 & 17 & 23.12 & 28.462 & 0.812 \\
2 & 20 & 34.91 & 35.658 & 0.979 \\
3 & 23 & 46.17 & 49.034 & 0.942 \\
4 & 14 & 13.3 & 22.898 & 0.581 \\
5 & 17 & 28.67 & 42.483 & 0.675 \\
6 & 18 & 18.86 & 23.487 & 0.803 \\
7 & 16 & 36.38 & 18.473 & 1.969 \\
8 & 16 & 14.18 & 23.361 & 0.607 \\
9 & 18 & 21.22 & 29.960 & 0.708 \\
Total & 159 & 236.81 & 273.816 & 0.865 \\
\hline
\end{tabular}

L.G.: linkage group; N.M. number of markers; G. size: genome size between the first and last marker of the LG. R.R. average recombination rate.

All the 159 mapped markers were anchored to the reference clementine genome [37] to evaluate the syntheny and the collinearity of the citrumelo genetic map with the reference genome. The syntheny of the citrumelo genetic map with the clementine genome assembly was globally high (93\% with 148 syntenic markers out of 159), however, 11 markers displayed discrepancies between scaffolds and LGs attachments (Figure 4). In addition to markers from scaffold 4, LG4 clustered two markers physically located on scaffold 2 (P2_2954832) and 6 (P6_3130249). LG8 clustered most markers of scaffold 8 but also two markers physically located on scaffold 3 (P3_34692989, P3_35766871) and two others on scaffold 9 (P9_13577432, P9_12062066). Four markers of scaffold 5 (P5_18108508, P5_12913997, P5_15626299, P5_14956622) were linked in LG7. One marker of scaffold 8 (P8_16631925) was found in LG6.
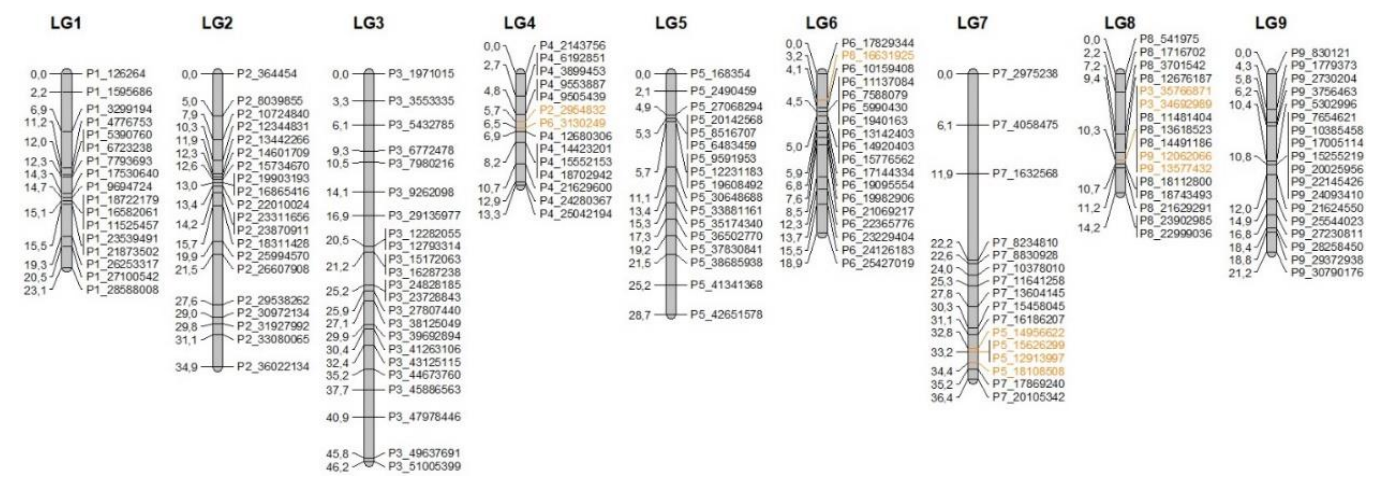

Figure 4. Genetic map of the tetraploid 4475 citrumelo. The non-syntenic markers are in orange. Details of LG (Linkage Group) are presented in Table 2. 
The Marey map (Figure 5) confirmed the high synteny and revealed very good collinearity with the clementine genome assembly for all chromosomes. Only four syntenic markers on LG2 (P2_18311428), 3 (P3_29135977), 6 (P6_17829344) and 7 (P7_1632568) displayed a different order in the citrumelo genetic map and the reference clementine genome assembly. The average rate of recombination ranged from $0.58 \mathrm{cM} / \mathrm{Mb}$ in $\mathrm{Chr} 4$ to $1.97 \mathrm{cM} / \mathrm{Mb}$ in $\mathrm{Chr} 7$ with an average of $0.87 \mathrm{cM} / \mathrm{Mb}$ (Table 2).

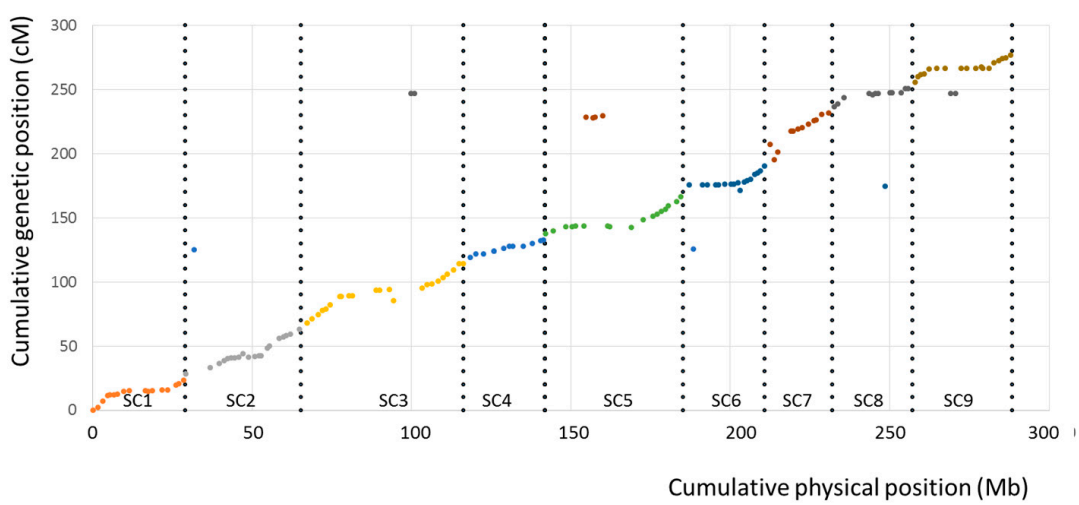

Figure 5. Marey map plot constructed with the 159 genetically mapped SNPs; $x$ axis, physical positions on the clementine reference genome (the dotted vertical lines delimit the 9 scaffold); $y$ axis, positions on the tetraploid citrumelo genetic map. Each color corresponds to one linkage group.

\subsection{Parental Heterozygosity Restitution and Meiotic Inheritance Analysis}

Given that genetic mapping revealed some situations of no-syntheny or no-collinearity, we analyzed parental heterozygosity restitution (PHR) and preferential chromosome pairing (PP) along the genome in agreement with the genetic map structure. PHR was determined for each marker, and for each chromosome, PP was estimated from four syntenic markers located around the centromere according to Aleza et al. [54,57].

For the population of diploid citrumelo gametes, we used the same matrix as that used for genetic mapping. The average PHR over the 125 gametes and 159 markers was $87.40 \%$ while Citrus and Poncirus homozygosity accounted for respectively $6.37 \%$ and $6.21 \%$. PHR varied between markers from 0.73 to 0.98 with variations between chromosomes and along the same chromosome (Figure 6).

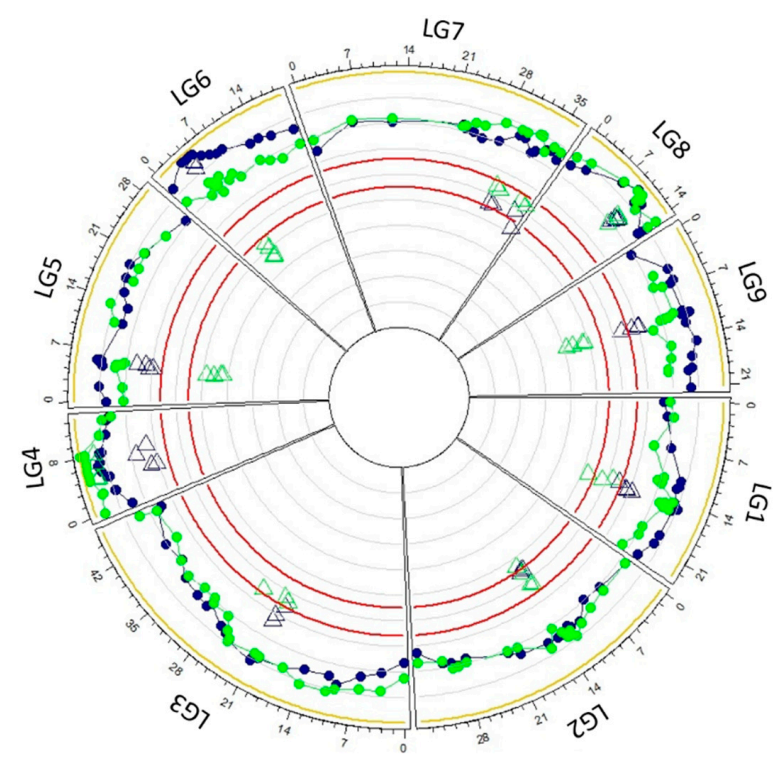

Figure 6. Parental heterozygosity restitution by diploid gametes (circle) and preferential chromosome pairing (triangle) for tetraploid citrumelo (blue) and citrandarin (green). Red line: limit of the range of PHR variation in the case of full tetrasomy (between 0.66 with no double reduction and 0.55 in the case of maximum double reduction); Yellow line: PHR $=1$, in the case of complete disomic segregation. 
Despite these intra-chromosomal variations, significant differences between chromosomes were revealed by a Kruskal-Wallis test ( $p$-value $<2.2 \times 10^{-16}$ ) and so a Wilcoxon test ( $p$-value $<0.05$ ) was performed to identify which chromosomes showed differential PHR. Chromosomes 6, 8 and 4 had the highest PHR rate, between $0.942 \pm 0.022$ and $0.902 \pm 0.014$. Chromosomes 9,5 and 1 had a PHR around $0.885 \pm 0.013$ and $0.865 \pm 0.021$. Chromosomes 3,2 and 7 had the lowest PHR, ranging from $0.842 \pm 0.020$ to $0.821 \pm 0.016$ (Table 3 and Figure S3).

Table 3. Parameters of the meiotic behaviors of the tetraploid 4475 citrumelo and tetraploid citrandarin.

\begin{tabular}{ccccc}
\hline \multirow{2}{*}{ Chromosome } & \multicolumn{2}{c}{ Citrumelo } & \multicolumn{2}{c}{ Citrandarin } \\
\cline { 2 - 5 } & PHR (rank) & PP (rank) & PHR (rank) & PP (rank) \\
\hline Chr1 & $0.865 \pm 0.021(\mathrm{de})$ & $0.683 \pm 0.024(\mathrm{~d})$ & $0.817 \pm 0.018(\mathrm{~cd})$ & $0.565 \pm 0.048(\mathrm{~d})$ \\
Chr2 & $0.824 \pm 0.016(\mathrm{f})$ & $0.561 \pm 0.007(\mathrm{e})$ & $0.831 \pm 0.016(\mathrm{bcd})$ & $0.587 \pm 0.042(\mathrm{~cd})$ \\
Chr3 & $0.842 \pm 0.020(\mathrm{ef})$ & $0.685 \pm 0.039(\mathrm{~d})$ & $0.848 \pm 0.020(\mathrm{bc})$ & $0.633 \pm 0.010(\mathrm{c})$ \\
Chr4 & $0.902 \pm 0.014(\mathrm{bc})$ & $0.738 \pm 0.029(\mathrm{c})$ & $0.957 \pm 0.023(\mathrm{a})$ & $0.946 \pm 0.002(\mathrm{a})$ \\
Chr5 & $0.882 \pm 0.015(\mathrm{~cd})$ & $0.722 \pm 0.027(\mathrm{c})$ & $0.842 \pm 0.018(\mathrm{bcd})$ & $0.447 \pm 0.029(\mathrm{e})$ \\
Chr6 & $0.942 \pm 0.022(\mathrm{a})$ & $0.942 \pm 0.011(\mathrm{a})$ & $0.812 \pm 0.013(\mathrm{~d})$ & $0.488 \pm 0.029(\mathrm{e})$ \\
Chr7 & $0.821 \pm 0.016(\mathrm{f})$ & $0.558 \pm 0.027(\mathrm{e})$ & $0.855 \pm 0.018(\mathrm{~b})$ & $0.631 \pm 0.006(\mathrm{c})$ \\
Chr8 & $0.926 \pm 0.019(\mathrm{ab})$ & $0.821 \pm 0.011(\mathrm{~b})$ & $0.935 \pm 0.010(\mathrm{a})$ & $0.825 \pm 0.023(\mathrm{~b})$ \\
Chr9 & $0.885 \pm 0.013(\mathrm{~cd})$ & $0.678 \pm 0.031(\mathrm{~d})$ & $0.810 \pm 0.013(\mathrm{~d})$ & $0.451 \pm 0.034(\mathrm{e})$ \\
\hline Whole genome & $0.874 \pm 0.008$ & $0.71 \pm 0.039$ & $0.854 \pm 0.009$ & $0.620 \pm 0.055$ \\
\hline
\end{tabular}

PP: Preferential pairing; PHR: parental heterozygosity restitution. PHR rank based on Kruskal Wallis and Wilcoxon test and PP rank based on ANOVA followed by a Newman-Keuls test. Values with the same letter in brackets did not represent significant differences.

PP also displayed significant variations between chromosomes as confirmed by a one-way ANOVA $\left(p\right.$-value $\left.<2.2 \times 10^{-16}\right)$ followed by a Newman-Keuls test $(p$-value $<0.05)$. Chromosome 6 and 8 had the highest PP values with $0.942 \pm 0.011$ and $0.821 \pm 0.011$, respectively. Chromosome 4 and 5 had similar PP rates varying between $0.738 \pm 0.0290 .722 \pm 0.027$. Chromosomes 3,1 and 9 varied between $0.685 \pm 0.039$ and $0.678 \pm 0.03$, while chromosomes 2 and 7 had the lowest PP rates of $0.561 \pm 0.007$ and $0.558 \pm 0.027$, respectively (Table 3 and Figure S3).

For the population of diploid citrandarin gametes, the same filters were applied for markers and the same individual selection as for citrumelo. The resulting matrix consisted of 58 gametes and 158 markers, among which 153 were shared with the citrumelo matrix. The average missing data rate was $2.53 \%$. The average PHR was $85.50 \%$ while Citrus and Poncirus homozygosity accounted for respectively, $8.71 \%$ and $5.79 \%$. PHR varied between markers from 0.74 to 1 (Figure 6) and significant differences in PHR between chromosomes were revealed by a Kruskal-Wallis test ( $p$-value $<$ $\left.7.636 \times 10^{-15}\right)$ followed by a Wilcoxon test $(p$-value $<0.05)$. Chromosome 4 and 8 had the highest PHR with respectively, $0.957 \pm 0.023$ and $0.935 \pm 0.010$. Chromosomes 7, 3, 5 and 2 had close PHR rates varying between $0.855 \pm 0.018$ and $0.831 \pm 0.016$. Chromosomes 1,6 and 9 had PHR from $0.817 \pm 0.018$ to $0.810 \pm 0.01$ (Table 3 and Figure S3).

PP varied significantly between chromosomes. A one-way ANOVA ( $p$-value $\left.<2.2 \times 10^{-16}\right)$ and a Newman-Keuls test $(p$-value $<0.05)$ showed the highest PP values for chromosome $4(0.946 \pm 0.002)$ and $8(0.825 \pm 0.023)$. Chromosomes $3,7,2$ had similar values ranging from $0.633 \pm 0.010$ and $0.587 \pm 0.042$. Chromosome 1 had a PP of $0.565 \pm 0.048$ and the lowest PP values were measured for chromosomes 6, 9 and 5 (from $0.488 \pm 0.029$ to $0.447 \pm 0.034$ (Table 3 and Figure S3).

A two-way ANOVA ( $p$-value $<2.2 \times 10^{-16}$ ) followed by a Newman-Keuls test $(p$-value $<0.05$ ) were used to compare PP values between citrumelo and citrandarin gamete populations. Similar PP were observed for chromosome 8 while significant variations were observed for the other chromosomes. Chromosomes 1, 5, 6 and 9 had significantly higher PP in citrumelo, while chromosomes 4 and 7 had higher PP in citrandarin. 


\subsection{Intergeneric Recombination and Genetic Structure of the Diploid Citrumelo and Citrandarin Gametes}

For each chromosome of each gamete, we estimated the number of intergeneric recombinations during meiosis producing diploid gametes as the number of genotyping changes between successive markers, as ordered on the genetic map.

The estimated number of inter-generic recombinations in meiosis producing diploid citrumelo gametes ranged from 0 to 13 with an average of 4.90 (Figure 7). Seven gametes (5.6\%) displayed no intergeneric recombination and were thus fully heterozygous and identical to the original diploid citrumelo 4475 . Half the gametes displayed no more than four recombinations and only $7.2 \%$ displayed more than nine recombinations (on average, one per chromosome). At linkage group level, the proportion of gametes with no intergeneric recombination ranged from $51.2 \%$ for LG3 to $79.2 \%$ for LG4. The percentage of gametes displaying at least two crossovers ranged from $5.6 \%$ for chromosomes 4 and 8 to $26.4 \%$ for chromosome 3 (Table S5).

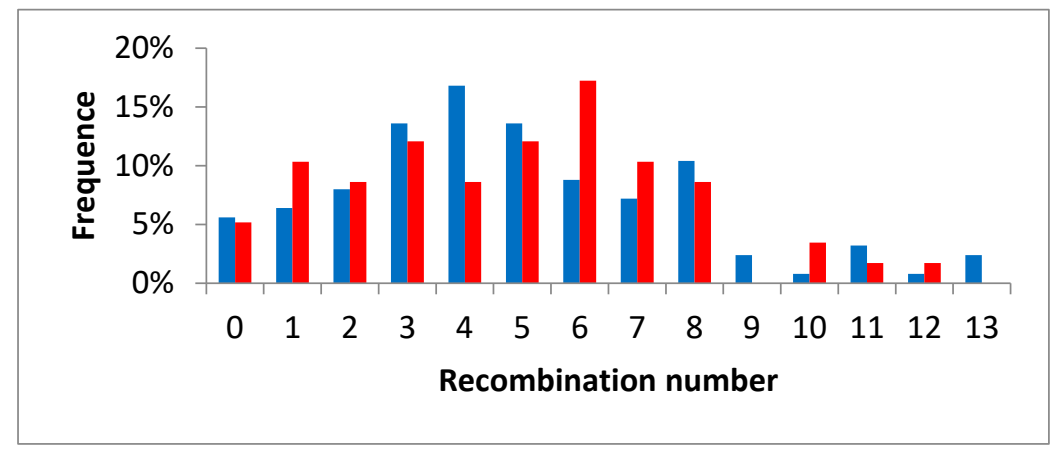

Figure 7. Distribution of the number of recombinations per gamete estimated from the citrumelo (blue) and citrandarin (red) gamete populations.

In citrandarin, the number of recombinations per diploid gamete ranged from 0 to 12 with an average of 4.78 (Figure 7). Three gametes (5.2\%) displayed no recombination over the whole genome. A total of $44.8 \%$ of the gamete displayed less than four recombinations, while only $6.9 \%$ displayed more than nine recombinations. At linkage group level, the proportion of gametes with no intergeneric recombination ranged from $58.6 \%$ for LG3 to $86.2 \%$ for LG8. The percentage of gametes displaying at least two crossovers ranged from $1.72 \%$ for chromosome 8 to $22.4 \%$ for chromosome 3 (Table S5).

We analyzed the dissimilarity among all the gametes, the ancestral genera and the diploid citrumelo 4475 and citrandarin that generated our tetraploid parents by chromosome doubling. The average dissimilarity between the diploid gametes and the diploid citrumelo and citrandarin was low $(0.063 \pm$ 0.007 for the diploid citrumelo gametes and similar $0.073 \pm 0.013$ for the citrandarin ones, (Figure 8A). Respectively $80.8 \%$ and $70.7 \%$ of the citrumelo and citrandarin diploid gametes displayed equal or more than $90 \%$ similarity with their corresponding diploid rootstock genotypes (citrumelo $44752 \mathrm{x}$ and citrandarin 2x). The neighbor-joining tree analysis (Figure $8 \mathrm{~B}$ ) revealed a similar pattern of intergeneric diversity for the two gamete populations centered on the diploid citrumelo 4475 and citrandarin. 


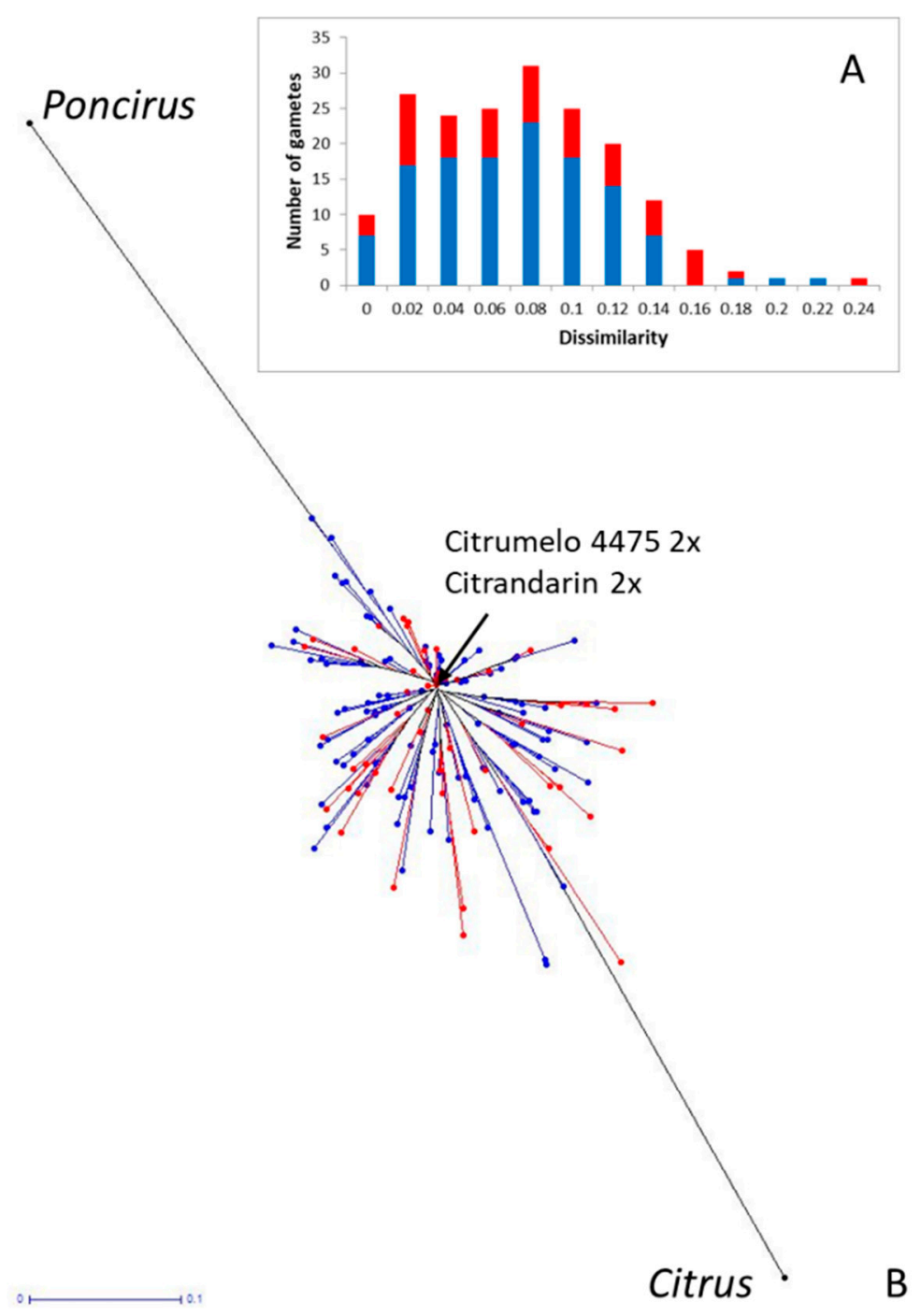

Figure 8. Genetic diversity of diploid gametes of Citrumelo 4475 (blue) and Citrandarin (red). (A) histogram of dissimilarity with the diploid intergeneric parent. (B) NJ tree of the gamete population, ancestor genera and intergeneric parents.

\section{Discussion}

\subsection{A set of 159 KAPar SNP Markers Fully Distinguishing Poncirus from Citrus Species was Validated}

With the development of next-generation sequencing, SNPs have become the most important resources for developing citrus molecular markers from transcriptomic [58,74] and genomic data $[37,38,75]$. An efficient SNP genotyping method was developed for scalable experiments using competitive allele amplification (KASPar@ technology) [53,76]. It proved to be useful for allele dosage in polyploid citrus [77]. Curk et al. [39,78] developed a set of KASPar SNP markers specific to four ancestral taxa of cultivated Citrus (C. maxima, C. micrantha, C. medica, and C. reticulata). The set was expanded for $C$. micrantha with 158 SNPs mined from GBS data to analyze the meiotic behavior of the tetraploid 'Giant Key' lime and to establish its genetic map [58]. Before the present work, only a few P. trifoliata dSNPs have been developed to distinguish zygotic from nucellar seedlings of intergeneric rootstocks [69].

To analyze meiotic behavior and perform genetic mapping of tetraploid intergeneric hybrids between Citrus and Poncirus, we developed a new set of SNPs that distinguish Citrus from Poncirus. GBS data were useful to identify 7882 DSNPs dispersed throughout the genome. Among them, 192 
markers were selected according to their dispersion over the genome, their location on a gene and the absence of additional polymorphism closer than 50 bases. This selection produced $82.8 \%$ (159) successful markers, i.e., similar to the $83.6 \%$ obtained by Ahmed et al. [58] using the same strategy for C. micrantha DSNPs. Among the 159 efficient markers, eight displayed apparent homozygosity in some intergeneric hybrids whereas they fully distinguished Citrus from Poncirus accessions, revealing the existence of null allele in heterozygosity in some Poncirus or Citrus parents of the intergeneric hybrids. As expected, the 151 other markers displayed heterozygosity in all F1 intergeneric hybrids tested. Most (119) of the Citrus/Poncirus diagnostic markers distinguished Poncirus from the five related genera belonging to the Aurantioideae subfamily. We can therefore consider they correspond to mutations that occurred during the separation of the Poncirus genus from the other true citrus genera and that they are P. trifoliata dSNPs. Efficient evaluation of allele doses with the method described by Cuenca et al. [53] allowed us to infer the diploid gamete genotypes and hence to analyze the inheritance of the tetraploid citrumelo and citrandarin along the genome. This set of markers will be useful for other analyses of Citrus/Poncirus intergeneric hybrids requiring low/medium marker density.

\subsection{The Tetraploid Citrumelo Genetic Map Confirms the Large Synteny and Co-Linearity between Citrus and Poncirus Genomes}

Several comparative genetic mapping studies already revealed high synteny and collinearity among Citrus species. Bernet et al. [79] observed marker collinearity in fragmented maps of sour orange, pummelo and 'Fortune' mandarin. The results for the C. reticulata/C. maxima gene pool were confirmed by saturated genetic maps of clementine, sweet orange and pummelo [80] with complete syntheny and high conservation of the linear order of markers. More recent high-density genetic maps established with NGS or array approaches confirmed the high consensus of genetic maps in this gene pool [81-83]. An early comparative genetic mapping study between C. sinensis and P. trifoliata suggested overall important synteny and collinearity [84] with however a few inversions between shared loci. Similar high levels of synteny and collinearity have also been observed between Fortune 'mandarin' and P. trifoliata [79]. More recently, the availability of a reference whole-genome sequence enabled comparison of high-density genetic maps and genome sequences and confirmed the good conservation of marker order across different species of Citrus and P. trifoliata, as described for mandarin and P. trifoliata $[83,85]$ or sweet orange and P. trifoliata $[86]$.

Our genetic map of the tetraploid citrumelo was anchored on the clementine reference genome and displayed $93 \%$ of synteny. Among the 11 non-syntenic markers, four successive markers of the clementine scaffold 5 were linked in the LG7 of the tetraploid citrumelo. Such a difference from the clementine reference genome was also observed in the same genomic region in high-density genetic maps of $C$. sinensis and P. trifoliata established from RADSeq data [86]. The same work also revealed a region of $C$. sinensis at the start of scaffold 2 linked in the LG4, as we observed for marker P2_2954832, and for regions of scaffolds 3 and 9 located in LG8 as we observed for markers (P3_34692989, P3_35766871, P9_13577432 and P9_12062066). In the same way, Huang et al. [86] observed in the LG3 of both the clementine and P. trifoliata maps, a misplaced region of scaffold 3 of the clementine assembly, where our badly positioned P3_29135977 marker is located. Most of the above-mentioned discrepancies between the tetraploid citrumelo genetic map and the clementine reference genome were also observed in GBS high-density genetic maps of 'Fortune' mandarin, 'Ellendale' tangor [58], clementine and Cleopatra mandarin (our unpublished results). Therefore, it appears that most of the apparent non-syntenic or non-colinear markers are rather due to minor errors in the clementine genome assembly than to real structural variations between citrumelo and clementine. The analysis of the meiotic parameter along the genome was performed according to the citrumelo genetic map.

\subsection{The Two Tetraploid Intergeneric Hybrids Display Intermediate Inheritance with a Disomic Tendency}

The inheritance patterns of molecular markers are powerful tools for determining meiotic behavior in polyploid species. They have been successfully used in citrus for doubled diploids $[47,57,58,87]$ 
and somatic hybrids $[46,73,88]$. Indeed, the genetic structure of diploid gamete populations produced by tetraploid parents and particularly parental heterozygosity restitution depends on preferential chromosome pairing and on the double reduction rate with two extreme models, disomic and tetrasomic $[42,44,89]$. In allotetraploids, each chromosome pairs only with its homologous form during meiosis and only bivalents are formed [42]. This results in disomic inheritance with the transmission of $100 \%$ of the interspecific heterozygosity by each gamete. In the Aurantioideae subfamily, this pattern was revealed for the tetraploid Clausena excavata [90]. In autotetraploids, the presence of four homologous chromosomes results in equal opportunities to pair at meiosis, leading to tetrasomic inheritance with potential multivalent formation. For doubled diploids, it hypothetically leads to $66 \%$ restitution of the parental heterozygosity in the absence of double reduction [57,91]. In cases where parents are divergent but have retained sufficient homology to prevent exclusive preferential pairing, intermediate inheritance patterns between disomic and tetrasomic can be expected [44]. Stift et al. [44] developed a likelihood-based approach to evaluate whether disomic, intermediate or tetrasomic inheritances best fitted the segregation of genetic markers and to estimate preferential pairing and double reduction (DR) rates. Aleza et al. [57] simplified this method for doubled diploids and diallelic duplex markers.

We applied the method of Aleza et al. [57] to analyze preferential pairing in the tetraploid citrumelo and citrandarin using centromeric and pericentromeric markers with the assumption of no double reduction. In both intergeneric hybrids, we found high PHR values (an average of $87.4 \%$ for citrumelo and $85.5 \%$ for citrandarin) beyond the ranges expected for strict tetrasomic or disomic inheritances. Preferential pairing analysis revealed intermediate inheritance behavior with preferential disomic tendency ( $\mathrm{PP}=0.71 \pm 0.04$ for citrumelo and $0.62 \pm 0.06$ for citrandarin). A similar tendency to disomic segregation was already observed in an intergeneric somatic hybrid between 'Willow Leaf' mandarin and Poncirus trifoliata cv 'Pomeroy' with an average PP of $0.72 \pm 0.05$ [46]. Preferential disomic inheritance was also observed in tetraploid limes resulting from chromosome doubling of Mexican limes [47,58]. Conversely, meiotic studies of tetraploid accessions of the C. reticulata/C. maxima gene pool revealed preferential tetrasomic inheritance. This was the case of doubled diploids of clementine [57] and 'Moncada' mandarin [87] as well as for a somatic hybrid between 'Nova' tangelo and 'HB' pummelo [88]. Rouiss et al. [47] suggested that the PP rate, and more generally meiotic behavior, is determined by the phylogenomic structure of the tetraploid parents. The doubled diploid 'Mexican' lime has two copies of C. micrantha and C. medica genomes, while clementine, 'Moncada' mandarin and the 'Nova' tangelo + ' $\mathrm{HB}$ ' pummelo are admixtures of $C$. maxima and $C$. reticulata. Whole genome resequencing data [38] and GBS data [40] revealed much greater differentiation between C. micrantha and C. medica than between C. reticulata and C. maxima. Recent whole nuclear genome resequencing data also revealed marked differentiation between Poncirus trifoliata and the Citrus species clade [38]. The preferential disomic inheritance observed in our doubled diploid citrumelo and citrandarin as well as in a mandarin + Poncirus somatic hybrid [46] is in agreement with this significant genomic differentiation between Citrus and Poncirus and with the cytogenetic observation of a high percentage of bivalents during the meiosis of an intergeneric citrus somatic hybrid between 'Cleopatra' mandarin and 'Argentine' trifoliate orange (unpublished results mentioned in Chen et al. [92]). However, the long-known intergeneric sexual compatibility at the diploid level [93] proves that the remaining homology is still sufficient to allow Citrus and Poncirus chromosome pairing and explains why intergeneric hybrids do not display strict disomic inheritance at tetraploid level.

Significant differences of preferential pairing were found between chromosomes in the same parent and between the two intergeneric hybrids. It was close to disomic inheritance (PP $>0.9)$ for chromosome 6 in citrumelo and chromosome 4 in citrandarin. Intermediate behavior with preferential disomic tendency $(0.9>\mathrm{PP}>0.5)$ was observed for chromosomes $1,2,3,4,5,7,8$ and 9 in citrumelo and chromosomes 1, 2, 3, 7 and 8 in citrandarin. Intermediate inheritance (no significant difference from 0.5 in PP) was concluded for chromosomes 5, 6 and 9 in citrandarin. Such variations in PP between chromosomes have already been described in sugarcane [50], autotetraploid pacific oysters [94] 
and tetraploid 'Giant Ley' lime [58]. The difference in PP rates between the chromosomes could be explained by variations in the extent of differentiation between the different sets of chromosomes, as proposed by Stebbins [95]. Interestingly, none of the nine chromosomes of the two inter-generic hybrids displayed tetrasomic inheritance, and genetic mapping provided no evidence for structural variations between Citrus and Poncirus genomes, suggesting that pairing is more affected by overall differentiation than by discrete local major structural variations. The molecular mechanisms that regulate homologous chromosome pairing have mainly been studied in polyploidy grass. Knowledge remains limited, although several hypothesis have been proposed [96]. The first hypothesis is the preexistence of the pairing regulators in diploid progenitors $[97,98]$. The second assumes that regulators of chromosome pairing emerge during or immediately after the formation of polyploids, through one or multiple, successive mutations $[99,100]$. The third suggests that regulators of chromosome pairing can be transferred via accessory B chromosomes [101]. No cytogenetic work has described the presence of B chromosomes in Citrus or Poncirus genomes and so the last model does not appear to be applicable in citrus. Preferential pairing has been observed in the three analysed intergeneric tetraploid hybrids resulting directly from somatic hybridization [46] or chromosome doubling of intergeneric diploid hybrids (the present work). It seems unlikely that similar independent mutations occurred in the three tetraploid intergeneric hybrids just after their formation, thereby ruling out the second hypothesis. Taking into account the full fertility of diploid intergeneric hybrids (and thus good homeologous pairing at diploid level), the first hypothesis should be compatible if the pairing regulator genes under consideration are up-regulated in tetraploids or act in a competitive way that is not applicable in intergeneric diploid hybrids.

4.4. Intergeneric Recombination Occurs but at Relatively Low Frequency and the Diploid Citrumelo Gametes Transmit a Large Part of the Intergeneric Heterozygosity of the Original Diploid 4475 Citrumelo Rootstock

Despite predominant disomic inheritance, we observed interspecific recombination in the nine citrus chromosomes. Their rates ranged from 0.58 in chromosome 4 to $1.97 \mathrm{cM} / \mathrm{Mb}$ in chromosome 7 , respectively. These rates were negatively correlated with preferential pairing of the different chromosomes. The apparent average recombination rate $(0.87 \mathrm{cM} / \mathrm{Mb})$ of the tetraploid citrumelo was similar to that of the predominantly disomic tetraploid 'Giant Key' lime (0.99 cM/Mb; [58]) but close to 3.6 times less than the one estimated for the predominantly tetrasomic tetraploid clementine $(3.21 \mathrm{cM} / \mathrm{Mb} ;[57,58])$. The reduction in the apparent recombination rate of the tetraploid citrumelo compared with the tetraploid clementine can basically be explained by its intermediary inheritance with disomic tendency. High preferential pairing strongly limits the proportion of gametes that can undergo intergeneric chiasmata and consequently intergeneric recombination, which was the only observable in doubled diploids of F1 intergeneric hybrids. In addition to the preferential disomic inheritance behavior in tetraploid organisms, the divergence between parental genomes may play a role in the variation in the recombination frequency of hybrids [102-107] whatever the ploidy level. High density genetic mapping of the diploid citrumelo should will make it possible to compare the intergeneric recombination rate with that of diploid Citrus and Poncirus species and to test the hypothesis that sequence divergence can limit the Citrus/Poncirus recombination in situation of homeologous pairing. The Marey map of the tetraploid citrumelo displays typical strong reduction of recombination in centromeric and pericentromeric areas, as previously described for the different saturated maps of diploid Citrus and Poncirus [80-83,86,108-110]. We observed similar pattern of intergeneric recombination for the tetraploid citrandarin.

\subsection{Implications for Citrus Rootstock Breeding}

Citrus breeding is hampered by complex genome structures, certain features of reproductive biology such as self-incompatibility and sterility, the difficulty and cost of screening large progenies and a long juvenile stage. However, breeders can take advantage of vegetative propagation including apomictic seeds for rootstock multiplication that allow clonal propagation of elite genotypes regardless of the complexity of their genome [111]. Consequently, citrus breeding strategies are generally based 
on very few cycles of variability induction (sexual or somatic hybridization, induced mutagenesis) followed by direct selection of cultivars or rootstock. In this context, it is crucial to optimize transfer of the genetic gains obtained by selection at the parental level to the progenies.

Today, diploid F1 intergeneric hybrids between Citrus and Poncirus represent very important rootstock for the world citrus industry. Most of their genetic value comes from the combination of favorable traits from Citrus (tolerance to abiotic stresses including salinity, water deficit, calcareous soils) and Poncirus (resistance/tolerance to diseases and pests such as tristeza virus, Phytophthora, nematodes; cold tolerance). Such value is based on dominant inheritance in full intergeneric heterozygous structures. Taking advantage of spontaneous chromosome doubling in nuclear cells, doubled diploid lines were selected for the most interesting intergeneric citrange, citrandarin and citrumelo [11,35]. To further optimize breeding using these intergeneric tetraploids as sexual parents (tetrazyg strategy; [30]), it is therefore essential to transmit a large part of the parental intergeneric heterozygosity to the progenies in order to prevent overall breakage of the favorable complex multilocus genotypic structure selected at the diploid level.

The present work reveals that differentiation between Citrus and Poncirus genomes results in preferential homologous pairing and high intergeneric heterozygosity transmission. The doubled diploid intergeneric hybrids produce gametes in which a very high proportion of the genome of the original diploid intergeneric hybrid has been transferred. It's even been observed that around 5\% of the diploid gametes transmitted it completely. Thus, the high phenotypic value selected at the level of the diploid intergeneric parent should have a very positive impact on the products of the tetrazig strategy when these doubled diploid parents are used. Moreover, the infrequent occurrence of homologous chromosome pairing offers an opportunity for intergeneric recombination, and the generation of novel allelic combinations that may be useful for selection against potential negative traits of the intergeneric hybrid. The tetrazyg strategy using Citrus/Poncirus intergeneric tetraploid parents thus offers the advantage of largely adding dominant traits of the parents generally highlighted for somatic hybridization plus the potential for limited intergeneric recombination.

\section{Conclusions}

A set of 159 new KASPar SNP markers fully distinguishing Poncirus trifoliata from Citrus species was successfully developed from polymorphisms mined in GBS data and used to establish a genetic map of the tetraploid citrumelo and to analyze the meiotic behavior of tetraploid citrumelo and citrandarin. The tetraploid citrumelo genetic map was highly syntenic and colinear with the clementine reference genome. Apparent recombination was limited compared with the previous diploid citrus genetic map and the tetraploid clementine map. This was explained by high preferential chromosome pairing resulting in intermediate inheritance with disomic tendency thereby limiting the proportion of gametes that can undergo interspecific chiasmata and consequently intergeneric recombination. This inheritance model was also observed in citrandarin and was associated with a high level of intergeneric heterozygosity transmission by the diploid gametes. Such inheritance should be highly favorable for rootstock breeding at tetraploid level. Indeed, the doubled-diploid intergeneric hybrids produce gametes in which a very high proportion of the genome of the original diploid intergeneric hybrid has been transferred. It is therefore expected that a significant part of the genetic value selected in the original diploid intergeneric rootstock will be transmitted to the tetraploid sexual progenies.

Supplementary Materials: The following are available online at http://www.mdpi.com/2073-4395/10/12/1961/s1, Table S1: Citrus germplasm used for GBS and Kaspar genotyping and as parents for intergeneric progenies, Table S2: Information on Poncirus DSNPs KASPar markers, Table S3: Detailed results of GBS analysis and identification of Poncirus diagnostic SNPs, Table S4: Genotyping of 54 citrus and relatives accessions with Poncirus DSNPs KASPar markers, Table S5: Analysis of intergeneric recombination rates in diploid Citrandarin and Citrumelo gametes, Figure S1: Physical distribution of the 192 selected DSNPs along the nine chromosomes., Figure S2: Neighbor-joining tree showing relationships between the 159 markers of the tetraploid Citrumelo genetic map, Figure S3: Graphical representations showing the meiotic behavior of the tetraploid 4475 Citrumelo and tetraploid Citrandarin. 
Author Contributions: P.O. and R.M. conceived and designed the experiments. Y.F. and S.B. generated the progenies. P.M., A.D. and L.C. performed the GBS analysis. L.C. and P.O. developed the dSNPs markers and analyzed the meiotic behavior. L.C. established the genetic map. L.C. and P.O. wrote the manuscript. All authors have read and agreed to the published version of the manuscript.

Funding: This study was funded by the Feder Cavalbio project and the Région Guadeloupe for Leny Calvez's PhD.

Conflicts of Interest: The authors declare that they have no conflict of interest.

\section{References}

1. Castle, W.S. A Career Perspective on Citrus Rootstocks, Their Development, and Commercialization. HortScience 2010, 45, 11-15. [CrossRef]

2. De Ollas, C.; Morillón, R.; Fotopoulos, V.; Puértolas, J.; Ollitrault, P.; Gómez-Cadenas, A.; Arbona, V. Facing Climate Change: Biotechnology of Iconic Mediterranean Woody Crops. Front. Plant Sci. 2019, 10, 427. [CrossRef] [PubMed]

3. Syvertsen, J.P.; Garcia-Sanchez, F. Multiple abiotic stresses occurring with salinity stress in citrus. Environ. Exp. Bot. 2014, 103, 128-137. [CrossRef]

4. Román, M.P.; Cambra, M.; Juárez, J.; Moreno, P.; Duran-Vila, N.; Tanaka, F.A.O.; Alves, E.; Kitajima, E.W.; Yamamoto, P.T.; Bassanezi, R.B.; et al. Sudden Death of Citrus in Brazil: A Graft-Transmissible Bud Union Disease. Plant Dis. 2004, 88, 453-467. [CrossRef]

5. Yang, Z.-N.; Ye, X.-R.; Choi, S.; Molina, J.; Moonan, F.; Wing, R.A.; Roose, M.L.; Mirkov, T.E. Construction of a $1.2-\mathrm{Mb}$ contig including the citrus tristeza virus resistance gene locus using a bacterial artificial chromosome library of Poncirus trifoliata (L.) Raf. Genome 2001, 44, 382-393. [CrossRef]

6. Spiegel-Roy, P.; Goldschmidt, E.E. The Biology of Citrus. In The Biology of Horticultural Crops; Cambridge University Press: Cambridge, UK, 1996; ISBN 978-0-521-33321-4.

7. Aritua, V.; Achor, D.; Gmitter, F.G.; Albrigo, G.; Wang, N. Transcriptional and Microscopic Analyses of Citrus Stem and Root Responses to Candidatus Liberibacter asiaticus Infection. PLoS ONE 2013, 8, e73742. [CrossRef]

8. Johnson, E.G.; Wu, J.; Bright, D.B.; Graham, J.H. Association of 'Candidatus Liberibacter asiaticus' root infection, but not phloem plugging with root loss on huanglongbing-affected trees prior to appearance of foliar symptoms. Plant Pathol. 2014, 63, 290-298. [CrossRef]

9. Da Graça, J.V.; Douhan, G.W.; Halbert, S.E.; Keremane, M.L.; Lee, R.F.; Vidalakis, G.; Zhao, H. Huanglongbing: An overview of a complex pathosystem ravaging the world's citrus: Citrus huanglongbing. J. Integr. Plant Biol. 2016, 58, 373-387. [CrossRef]

10. Ramadugu, C.; Keremane, M.L.; Halbert, S.E.; Duan, Y.P.; Roose, M.L.; Stover, E.; Lee, R.F. Long-Term Field Evaluation Reveals Huanglongbing Resistance in Citrus Relatives. Plant Dis. 2016, 100, 1858-1869. [CrossRef]

11. Ollitrault, P.; Germanà, M.A.; Froelicher, Y.; Cuenca, J.; Aleza, P.; Morillon, R.; Grosser, J.W.; Guo, W. Ploidy Manipulation for Citrus Breeding, Genetics, and Genomics. In The Citrus Genome; Gentile, A., La Malfa, S., Deng, Z., Eds.; Springer International Publishing: Cham, Switzerland, 2020; pp. 75-105. ISBN 978-3-030-15308-3.

12. Mouhaya, W.; Allario, T.; Brumos, J.; Andres, F.; Froelicher, Y.; Luro, F.; Talon, M.; Ollitrault, P.; Morillon, R. Sensitivity to high salinity in tetraploid citrus seedlings increases with water availability and correlates with expression of candidate genes. Funct. Plant Biol. 2010, 37, 674-685. [CrossRef]

13. Podda, A.; Checcucci, G.; Mouhaya, W.; Centeno, D.; Rofidal, V.; Del Carratore, R.; Luro, F.; Morillon, R.; Ollitrault, P.; Maserti, B.E. Salt-stress induced changes in the leaf proteome of diploid and tetraploid mandarins with contrasting Na+ and Cl- accumulation behaviour. J. Plant Physiol. 2013, 170, 1101-1112. [CrossRef]

14. Ruiz, M.; Quiñones, A.; Martínez-Alcántara, B.; Aleza, P.; Morillon, R.; Navarro, L.; Primo-Millo, E.; Martínez-Cuenca, M.-R. Effects of salinity on diploid (2x) and doubled diploid (4x) Citrus macrophylla genotypes. Sci. Hortic. 2016, 207, 33-40. [CrossRef]

15. De Souza, J.D.; Rodrigues, V.; Barigah, T.; Ollitrault, P.; Gesteira, A.d.S.; Morillon, R. Whole genome expression and hydraulic architecture of diploid and doubled diploid citrus seedlings in intra and interspecific contexts. Citrus Res. Technol. 2016, 37, 206-210. [CrossRef]

16. Oliveira, T.M.; Yahmed, J.B.; Dutra, J.; Maserti, B.E.; Talon, M.; Navarro, L.; Ollitraut, P.; Gesteira, A.D.; Morillon, R. Better tolerance to water deficit in doubled diploid 'Carrizo citrange' compared to diploid seedlings is associated with more limited water consumption. Acta Physiol. Plant. 2017, 39, 204. [CrossRef] 
17. Khalid, M.F.; Hussain, S.; Anjum, M.A.; Ahmad, S.; Ali, M.A.; Ejaz, S.; Morillon, R. Better salinity tolerance in tetraploid vs diploid volkamer lemon seedlings is associated with robust antioxidant and osmotic adjustment mechanisms. J. Plant Physiol. 2020, 244, 153071. [CrossRef] [PubMed]

18. Allario, T.; Brumos, J.; Colmenero-Flores, J.M.; Iglesias, D.J.; Pina, J.A.; Navarro, L.; Talon, M.; Ollitrault, P.; Morillon, R. Tetraploid Rangpur lime rootstock increases drought tolerance via enhanced constitutive root abscisic acid production. Plant Cell Environ. 2013, 36, 856-868. [CrossRef] [PubMed]

19. Dutra de Souza, J.; de Andrade Silva, E.M.; Coelho Filho, M.A.; Morillon, R.; Bonatto, D.; Micheli, F.; da Silva Gesteira, A. Different adaptation strategies of two citrus scion/rootstock combinations in response to drought stress. PLoS ONE 2017, 12, e0177993. [CrossRef] [PubMed]

20. Oustric, J.; Lourkisti, R.; Herbette, S.; Morillon, R.; Paolacci, G.; Gonzalez, N.; Berti, L.; Santini, J. Effect of Propagation Method and Ploidy Level of Various Rootstocks on the Response of the Common Clementine (Citrus clementina Hort. ex Tan) to a Mild Water Deficit. Agriculture 2020, 10, 321. [CrossRef]

21. Oustric, J.; Morillon, R.; Luro, F.; Herbette, S.; Lourkisti, R.; Giannettini, J.; Berti, L.; Santini, J. Tetraploid Carrizo citrange rootstock (Citrus sinensis Osb. X Poncirus trifoliata L. Raf.) enhances natural chilling stress tolerance of common clementine (Citrus clementina Hort. ex Tan). J. Plant Physiol. 2017, 214, 108-115. [CrossRef]

22. Oustric, J.; Morillon, R.; Ollitrault, P.; Herbette, S.; Luro, F.; Froelicher, Y.; Tur, I.; Dambier, D.; Giannettini, J.; Berti, L.; et al. Somatic hybridization between diploid Poncirus and Citrus improves natural chilling and light stress tolerances compared with equivalent doubled-diploid genotypes. Trees 2018, 32, 883-895. [CrossRef]

23. Oustric, J.; Quilichini, Y.; Morillon, R.; Herbette, S.; Luro, F.; Giannettini, J.; Berti, L.; Santini, J. Tetraploid citrus seedlings subjected to long-term nutrient deficiency are less affected at the ultrastructural, physiological and biochemical levels than diploid ones. Plant Physiol. Biochem. 2019, 135, 372-384. [CrossRef] [PubMed]

24. Ruiz, M.; Quiñones, A.; Martínez-Alcántara, B.; Aleza, P.; Morillon, R.; Navarro, L.; Primo-Millo, E.; Martínez-Cuenca, M.-R. Tetraploidy Enhances Boron-Excess Tolerance in Carrizo Citrange (Citrus sinensis L. Osb. $\times$ Poncirus trifoliata L. Raf.). Front. Plant Sci. 2016, 7, 701. [CrossRef] [PubMed]

25. Tan, F.-Q.; Tu, H.; Liang, W.-J.; Long, J.-M.; Wu, X.-M.; Zhang, H.-Y.; Guo, W.-W. Comparative metabolic and transcriptional analysis of a doubled diploid and its diploid citrus rootstock (C. junos cv. Ziyang xiangcheng) suggests its potential value for stress resistance improvement. BMC Plant Biol. 2015, 15, 89. [CrossRef] [PubMed]

26. Grosser, J.W.; Chandler, J.L. Somatic hybridization of high yield, cold-hardy and disease resistant parents for citrus rootstock improvement. J. Hortic. Sci. Biotechnol. 2000, 75, 641-644. [CrossRef]

27. Grosser, J.W.; Ollitrault, P.; Olivares-Fuster, O. Somatic hybridization in citrus: An effective tool to facilitate variety improvement. Vitro Cell. Dev. Biol.-Plant 2000, 36, 434-449. [CrossRef]

28. Guo, W.W.; Wu, R.C.; Cheng, Y.J.; Deng, X.X. Production and molecular characterization of Citrus intergeneric somatic hybrids between red tangerine and citrange. Plant Breed. 2007, 126, 72-76. [CrossRef]

29. Dambier, D.; Benyahia, H.; Pensabene-Bellavia, G.; Aka Kaçar, Y.; Froelicher, Y.; Belfalah, Z.; Lhou, B.; Handaji, N.; Printz, B.; Morillon, R.; et al. Somatic hybridization for citrus rootstock breeding: An effective tool to solve some important issues of the Mediterranean citrus industry. Plant Cell Rep. 2011, 30, 883-900. [CrossRef]

30. Grosser, J.W.; Gmitter, F.G. Protoplast fusion for production of tetraploids and triploids: Applications for scion and rootstock breeding in citrus. Plant Cell Tissue Organ Cult. PCTOC 2011, 104, 343-357. [CrossRef]

31. Guerra, D.; Schifino-Wittmann, M.T.; Schwarz, S.F.; Weiler, R.L.; Dahmer, N.; Souza, P.V.D. de Tetraploidization in citrus rootstocks: Effect of genetic constitution and environment in chromosome duplication. Crop Breed. Appl. Biotechnol. 2016, 16, 35-41. [CrossRef]

32. Ollitrault, P.; Froelicher, Y.; Dambier, D.; Seker, M. Rootstock breeding by somatic hybridisation for the mediterranean citrus industry. In Proceedings of the First International Citrus Biotechnology Symposium, 2000, Eliat, Israel, 29 November-3 December 1998; pp. 157-162.

33. Ollitrault, P.; Guo, W.; Grosser, J.W. Somatic hybridization. In Citrus Genetics, Breeding and Biotechnology; Khan Igar, A., Ed.; CAB International: Wallingford, UK, 2007; pp. 235-260.

34. Grosser, J.W.; Barthe, G.A.; Castle, B.; Gmitter, F.G., Jr.; Lee, O. The development of improved tetraploid citrus rootstocks to facilitate advanced production systems and sustainable citriculture in Florida. Acta Hortic. 2015, 1065, 319-327. [CrossRef]

35. Aleza, P.; Froelicher, Y.; Schwarz, S.; Agustí, M.; Hernández, M.; Juárez, J.; Luro, F.; Morillon, R.; Navarro, L.; Ollitrault, P. Tetraploidization events by chromosome doubling of nucellar cells are frequent in apomictic citrus and are dependent on genotype and environment. Ann. Bot. 2011, 108, 37-50. [CrossRef] [PubMed] 
36. Ruiz, M.; Pensabene-Bellavia, G.; Quiñones, A.; García-Lor, A.; Morillon, R.; Ollitrault, P.; Primo-Millo, E.; Navarro, L.; Aleza, P. Molecular Characterization and Stress Tolerance Evaluation of New Allotetraploid Somatic Hybrids Between Carrizo Citrange and Citrus macrophylla W. rootstocks. Front. Plant Sci. 2018, 9, 901. [CrossRef] [PubMed]

37. Wu, G.A.; Prochnik, S.; Jenkins, J.; Salse, J.; Hellsten, U.; Murat, F.; Perrier, X.; Ruiz, M.; Scalabrin, S.; Terol, J.; et al. Sequencing of diverse mandarin, pummelo and orange genomes reveals complex history of admixture during citrus domestication. Nat. Biotechnol. 2014, 32, 656-662. [CrossRef] [PubMed]

38. Wu, G.A.; Terol, J.; Ibanez, V.; López-García, A.; Pérez-Román, E.; Borredá, C.; Domingo, C.; Tadeo, F.R.; Carbonell-Caballero, J.; Alonso, R.; et al. Genomics of the origin and evolution of Citrus. Nature 2018, 554, 311-316. [CrossRef] [PubMed]

39. Curk, F.; Ollitrault, F.; Garcia-Lor, A.; Luro, F.; Navarro, L.; Ollitrault, P. Phylogenetic origin of limes and lemons revealed by cytoplasmic and nuclear markers. Ann. Bot. 2016, 117, 565-583. [CrossRef] [PubMed]

40. Ahmed, D.; Comte, A.; Curk, F.; Costantino, G.; Luro, F.; Dereeper, A.; Mournet, P.; Froelicher, Y.; Ollitrault, P. Genotyping by sequencing can reveal the complex mosaic genomes in gene pools resulting from reticulate evolution: A case study in diploid and polyploid citrus. Ann. Bot. 2019, 123, 1231-1251. [CrossRef] [PubMed]

41. Soltis, P.S.; Soltis, D.E. The role of genetic and genomic attributes in the success of polyploids. Proc. Natl. Acad. Sci. USA 2000, 97, 7051-7057. [CrossRef]

42. Stebbins, G.L. Types of Polyploids: Their Classification and Significance. In Advances in Genetics; Demerec, M., Ed.; University of California Press: Berkeley, CA, USA, 1947; Volume 1, pp. 403-429. ISBN 0065-2660.

43. Udall, J.A.; Wendel, J.F. Polyploidy and Crop Improvement. Crop Sci. 2006, 46, S3-S14. [CrossRef]

44. Stift, M.; Berenos, C.; Kuperus, P.; van Tienderen, P.H. Segregation Models for Disomic, Tetrasomic and Intermediate Inheritance in Tetraploids: A General Procedure Applied to Rorippa (Yellow Cress) Microsatellite Data. Genetics 2008, 179, 2113-2123. [CrossRef]

45. Jeridi, M.; Perrier, X.; Rodier-Goud, M.; Ferchichi, A.; D’Hont, A.; Bakry, F. Cytogenetic evidence of mixed disomic and polysomic inheritance in an allotetraploid (AABB) Musa genotype. Ann. Bot. 2012, 110, 1593-1606. [CrossRef]

46. Kamiri, M.; Stift, M.; Costantino, G.; Dambier, D.; Kabbage, T.; Ollitrault, P.; Froelicher, Y. Preferential Homologous Chromosome Pairing in a Tetraploid Intergeneric Somatic Hybrid (Citrus reticulata + Poncirus trifoliata) Revealed by Molecular Marker Inheritance. Front. Plant Sci. 2018, 9, 1557. [CrossRef] [PubMed]

47. Rouiss, H.; Bakry, F.; Froelicher, Y.; Navarro, L.; Aleza, P.; Ollitrault, P. Origin of C. latifolia and C. aurantiifolia triploid limes: The preferential disomic inheritance of doubled-diploid 'Mexican' lime is consistent with an interploid hybridization hypothesis. Ann. Bot. 2018, 121, 571-585. [CrossRef] [PubMed]

48. Allendorf, F.W.; Danzmann, R.G. Secondary tetrasomic segregation of MDH-B and preferential pairing of homeologues in rainbow trout. Genetics 1997, 145, 1083-1092. [PubMed]

49. Barone, A.; Li, J.; Sebastiano, A.; Cardi, T.; Frusciante, L. Evidence for tetrasomic inheritance in a tetraploid Solanum commersonii (+) S. tuberosum somatic hybrid through the use of molecular markers. Theor. Appl. Genet. 2002, 104, 539-546. [CrossRef]

50. Jannoo, N.; Grivet, L.; David, J.; D’Hont, A.; Glaszmann, J.-C. Differential chromosome pairing affinities at meiosis in polyploid sugarcane revealed by molecular markers. Heredity 2004, 93, 460-467. [CrossRef]

51. Bousalem, M.; Arnau, G.; Hochu, I.; Arnolin, R.; Viader, V.; Santoni, S.; David, J. Microsatellite segregation analysis and cytogenetic evidence for tetrasomic inheritance in the American yam Dioscorea trifida and a new basic chromosome number in the Dioscoreae. Theor. Appl. Genet. 2006, 113, 439-451. [CrossRef]

52. Landergott, U.; Naciri, Y.; Schneller, J.J.; Holderegger, R. Allelic configuration and polysomic inheritance of highly variable microsatellites in tetraploid gynodioecious Thymus praecox agg. Theor. Appl. Genet. 2006, 113, 453-465. [CrossRef]

53. Cuenca, J.; Aleza, P.; Navarro, L.; Ollitrault, P. Assignment of SNP allelic configuration in polyploids using competitive allele-specific PCR: Application to citrus triploid progeny. Ann. Bot. 2013, 111, 731-742. [CrossRef]

54. Aleza, P.; Cuenca, J.; Hernández, M.; Juárez, J.; Navarro, L.; Ollitrault, P. Genetic mapping of centromeres in the nine Citrus clementina chromosomes using half-tetrad analysis and recombination patterns in unreduced and haploid gametes. BMC Plant Biol. 2015, 15, 80. [CrossRef]

55. Rouiss, H.; Cuenca, J.; Navarro, L.; Ollitrault, P.; Aleza, P. Tetraploid citrus progenies arising from FDR and SDR unreduced pollen in $4 \times$ X 2x hybridizations. Tree Genet. Genomes 2017, 13, 10. [CrossRef] 
56. Rouiss, H.; Cuenca, J.; Navarro, L.; Ollitrault, P.; Aleza, P. Unreduced Megagametophyte Production in Lemon Occurs via Three Meiotic Mechanisms, Predominantly Second-Division Restitution. Front. Plant Sci. 2017, 8, 1211. [CrossRef] [PubMed]

57. Aleza, P.; Cuenca, J.; Juárez, J.; Navarro, L.; Ollitrault, P. Inheritance in doubled-diploid clementine and comparative study with SDR unreduced gametes of diploid clementine. Plant Cell Rep. 2016, 35, 1573-1586. [CrossRef] [PubMed]

58. Ahmed, D.; Curk, F.; Evrard, J.C.; Froelicher, Y.; Ollitrault, P. Preferential Disomic Segregation and C. micrantha/C. medica Interspecific Recombination in Tetraploid 'Giant Key' Lime; Outlook for Triploid Lime Breeding. Front. Plant Sci. 2020, 11, 939. [CrossRef] [PubMed]

59. Castle, B.; Stover, E. Rootstock refections: Swingle citrumelo update. Citrus Industry 2000, 81, 18-20.

60. Roose, M.L. Rootstocks. In Citrus Production Manual; Ferguson, L., Grafton-Cardwell, E.E., Eds.; University of California Agriculture and Natural Resources Communication Services: Oakland, CA, USA, 2014; pp. $95-105$.

61. Oueslati, A.; Salhi-Hannachi, A.; Luro, F.; Vignes, H.; Mournet, P.; Ollitrault, P. Genotyping by sequencing reveals the interspecific $\mathrm{C}$. maxima / C. reticulata admixture along the genomes of modern citrus varieties of mandarins, tangors, tangelos, orangelos and grapefruits. PLoS ONE 2017, 12, e0185618. [CrossRef] [PubMed]

62. Elshire, R.J.; Glaubitz, J.C.; Sun, Q.; Poland, J.A.; Kawamoto, K.; Buckler, E.S.; Mitchell, S.E. A Robust, Simple Genotyping-by-Sequencing (GBS) Approach for High Diversity Species. PLoS ONE 2011, 6, e19379. [CrossRef] [PubMed]

63. Sonah, H.; Bastien, M.; Iquira, E.; Tardivel, A.; Légaré, G.; Boyle, B.; Normandeau, É.; Laroche, J.; Larose, S.; Jean, M.; et al. An Improved Genotyping by Sequencing (GBS) Approach Offering Increased Versatility and Efficiency of SNP Discovery and Genotyping. PLoS ONE 2013, 8, e54603. [CrossRef]

64. Glaubitz, J.C.; Casstevens, T.M.; Lu, F.; Harriman, J.; Elshire, R.J.; Sun, Q.; Buckler, E.S. TASSEL-GBS: A High Capacity Genotyping by Sequencing Analysis Pipeline. PLoS ONE 2014, 9, e90346. [CrossRef]

65. Langmead, B.; Salzberg, S.L. Fast gapped-read alignment with Bowtie 2. Nat. Methods 2012, 9, 357-359. [CrossRef]

66. Danecek, P.; Auton, A.; Abecasis, G.; Albers, C.A.; Banks, E.; DePristo, M.A.; Handsaker, R.E.; Lunter, G.; Marth, G.T.; Sherry, S.T.; et al. The variant call format and VCFtools. Bioinformatics 2011, 27, 2156-2158. [CrossRef]

67. Nei, M. Analysis of gene diversity in subdivided populations. Proc. Natl. Acad. Sci. USA 1973, 70, 3321-3323. [CrossRef] [PubMed]

68. Perrier, X. Jacquemoud-Collet DARwin Software. 2006. Available online: http://darwin.cirad.fr/darwin (accessed on 8 December 2020).

69. Bruyère, S.; Luro, F.; Morillon, R.; Ollitrault, P. Poncirus phylogenetic diagnostic SNPs markers are useful to analyse zygotic rates in diploid and tetraploid Citrus $x$ Poncirus rootstock seedlings. In Abstract Book Sustainable Citriculture: The role of Applied Knowledge; Mattos, D., Fermino, C.E., Moreira, N.V., Alves de Azevedo, F., Della Coletta, F.H., Vicente Contador, Z.P., Eds.; IAPAR: Londrina, Brazil, 2016; p. 125.

70. Cuppen, E. Genotyping by Allele-Specific Amplification (KASPar). Cold Spring Harb. Protoc. 2007, 2007, pdb.prot4841. [CrossRef] [PubMed]

71. Grandke, F.; Ranganathan, S.; van Bers, N.; de Haan, J.R.; Metzler, D. PERGOLA: Fast and deterministic linkage mapping of polyploids. BMC Bioinform. 2017, 18, 12. [CrossRef] [PubMed]

72. Voorrips, R.E. MapChart: Software for the Graphical Presentation of Linkage Maps and QTLs. J. Hered. 2002, 93, 77-78. [CrossRef] [PubMed]

73. Kamiri, M.; Stift, M.; Srairi, I.; Costantino, G.; Moussadik, A.E.; Hmyene, A.; Bakry, F.; Ollitrault, P.; Froelicher, Y. Evidence for non-disomic inheritance in a Citrus interspecific tetraploid somatic hybrid between C. reticulata and C. limon using SSR markers and cytogenetic analysis. Plant Cell Rep. 2011, 30, 1415-1425. [CrossRef] [PubMed]

74. Chen, C.; Gmitter, F.G., Jr. Mining of haplotype-based expressed sequence tag single nucleotide polymorphisms in citrus. BMC Genom. 2013, 14, 746. [CrossRef]

75. Ollitrault, P.; Terol, J.; Garcia-Lor, A.; Bérard, A.; Chauveau, A.; Froelicher, Y.; Belzile, C.; Morillon, R.; Navarro, L.; Brunel, D.; et al. SNP mining in C. clementina BAC end sequences; transferability in the Citrus genus (Rutaceae), phylogenetic inferences and perspectives for genetic mapping. BMC Genom. 2012, 13, 13. [CrossRef] 
76. Garcia-Lor, A.; Ancillo, G.; Navarro, L.; Ollitrault, P. Citrus (Rutaceae) SNP Markers Based on Competitive Allele-Specific PCR; Transferability Across the Aurantioideae Subfamily. Appl. Plant Sci. 2013, 1, 1200406. [CrossRef]

77. Cuenca, J.; Aleza, P.; Juárez, J.; García-Lor, A.; Froelicher, Y.; Navarro, L.; Ollitrault, P. Maximum-likelihood method identifies meiotic restitution mechanism from heterozygosity transmission of centromeric loci: Application in citrus. Sci. Rep. 2015, 5, 9897. [CrossRef]

78. Curk, F.; Ancillo, G.; Ollitrault, F.; Perrier, X.; Jacquemoud-Collet, J.-P.; Garcia-Lor, A.; Navarro, L.; Ollitrault, P. Nuclear Species-Diagnostic SNP Markers Mined from 454 Amplicon Sequencing Reveal Admixture Genomic Structure of Modern Citrus Varieties. PLoS ONE 2015, 10, e0125628. [CrossRef]

79. Bernet, G.P.; Fernandez-Ribacoba, J.; Carbonell, E.A.; Asins, M.J. Comparative genome-wide segregation analysis and map construction using a reciprocal cross design to facilitate citrus germplasm utilization. Mol. Breed. 2010, 25, 659-673. [CrossRef]

80. Ollitrault, P.; Terol, J.; Chen, C.; Federici, C.T.; Lotfy, S.; Hippolyte, I.; Ollitrault, F.; Bérard, A.; Chauveau, A.; Cuenca, J.; et al. A reference genetic map of C. clementina hort. ex Tan.; citrus evolution inferences from comparative mapping. BMC Genom. 2012, 13, 593. [CrossRef] [PubMed]

81. Shimada, T.; Fujii, H.; Endo, T.; Ueda, T.; Sugiyama, A.; Nakano, M.; Kita, M.; Yoshioka, T.; Shimizu, T.; Nesumi, H.; et al. Construction of a citrus framework genetic map anchored by 708 gene-based markers. Tree Genet. Genomes 2014, 10, 1001-1013. [CrossRef]

82. Yu, Y.; Chen, C.; Gmitter, F.G. QTL mapping of mandarin (Citrus reticulata) fruit characters using high-throughput SNP markers. Tree Genet. Genomes 2016, 12, 77. [CrossRef]

83. Curtolo, M.; Soratto, T.A.T.; Gazaffi, R.; Takita, M.A.; Machado, M.A.; Cristofani-Yaly, M. High-density linkage maps for Citrus sunki and Poncirus trifoliata using DArTseq markers. Tree Genet. Genomes 2018, 14, 5. [CrossRef]

84. Chen, C.; Bowman, K.D.; Choi, Y.A.; Dang, P.M.; Rao, M.N.; Huang, S.; Soneji, J.R.; McCollum, T.G.; Gmitter, F.G. EST-SSR genetic maps for Citrus sinensis and Poncirus trifoliata. Tree Genet. Genomes 2007, 4, 1-10. [CrossRef]

85. Zheng, X.; Tang, Y.; Ye, J.; Pan, Z.; Tan, M.; Xie, Z.; Chai, L.; Xu, Q.; Fraser, P.D.; Deng, X. SLAF-Based Construction of a High-Density Genetic Map and Its Application in QTL Mapping of Carotenoids Content in Citrus Fruit. J. Agric. Food Chem. 2019, 67, 994-1002. [CrossRef]

86. Huang, M.; Roose, M.L.; Yu, Q.; Du, D.; Yu, Y.; Zhang, Y.; Deng, Z.; Stover, E.; Gmitter, F.G. Construction of High-Density Genetic Maps and Detection of QTLs Associated with Huanglongbing Tolerance in Citrus. Front. Plant Sci. 2018, 9, 1694. [CrossRef]

87. Garavello, M.; Cuenca, J.; Garcia-Lor, A.; Ortega, N.; Navarro, L.; Ollitrault, P.; Aleza, P. Male and female inheritance patterns in tetraploid 'Moncada' mandarin. Plant Cell Rep. 2020, 39, 335-349. [CrossRef]

88. Xie, K.-D.; Xia, Q.-M.; Wang, X.-P.; Liang, W.-J.; Wu, X.-M.; Grosser, J.W.; Guo, W.-W. Cytogenetic and SSR-marker evidence of mixed disomic, tetrasomic, and intermediate inheritance in a citrus allotetraploid somatic hybrid between 'Nova' tangelo and 'HB' pummelo. Tree Genet. Genomes 2015, 11, 112. [CrossRef]

89. Sybenga, J. Cytogenetics in Plant Breeding. In Monographs on Theoretical and Applied Genetics; Springer: Berlin/Heidelberg, Germany, 1992; Volume 17, ISBN 978-3-642-84085-2.

90. Froelicher, Y.; Luro, F.; Ollitrault, P. Analysis of meiotic behavior of the tetraploid Clausena excavata species by molecular marker segregation studies. In Proceedings of the 9th ISC International Society of Citriculture Congress, Orlando, FL, USA, 3-7 December 2000.

91. Sanford, J.C. Ploidy manipulations. In Methods in Fruit Breeding; Moore, J.N., Janick, J., Eds.; Purdue University Press: West Lafayette, IN, USA, 1983; pp. 100-123.

92. Chen, C.L.; Guo, W.W.; Yi, H.L.; Deng, X.X. Cytogenetic analysis of two interspecific Citrus allotetraploid somatic hybrids and their diploid fusion parents. Plant Breed. 2004, 123, 332-337. [CrossRef]

93. Cameron, J.W.; Garber, M.J. Identical-Twin Hybrids of Citrus x Poncirus from Strictly Sexual Seed Parents. Am. J. Bot. 1968, 55, 199-205. [CrossRef]

94. Curole, J.P.; Hedgecock, D. Estimation of Preferential Pairing Rates in Second-Generation Autotetraploid Pacific Oysters (Crassostrea gigas). Genetics 2005, 171, 855-859. [CrossRef] [PubMed]

95. Stebbins, G.L. Variation and Evolution in Plants; Columbia University Press: New York, NY, USA, $1950 ;$ p. 643.

96. Svačina, R.; Sourdille, P.; Kopecký, D.; Bartoš, J. Chromosome Pairing in Polyploid Grasses. Front. Plant Sci. 2020, 11, 1056. [CrossRef] [PubMed] 
97. Waines, J.G. A Model for the Origin of Diploidizing Mechanisms in Polyploid Species. Am. Nat. 1976, 110, 415-430. [CrossRef]

98. Jenczewski, E.; Alix, K. From Diploids to Allopolyploids: The Emergence of Efficient Pairing Control Genes in Plants. Crit. Rev. Plant Sci. 2004, 23, 21-45. [CrossRef]

99. Riley, R.; Law, C.N. Genetic Variation in Chromosome Pairing. In Advances in Genetics; Caspari, E.W., Thoday, J.M., Eds.; Academic Press: Cambridge, England, 1965; Volume 13, pp. 57-114. ISBN 0065-2660.

100. McGuire, P.E.; Dvořák, J. Genetic regulation of heterogenetic chromosome pairing in polyploid species of the genus triticum. Can. J. Genet. Cytol. 1982, 24, 57-82. [CrossRef]

101. Sears, E.R. Genetic control of chromosome pairing in wheat. Annu. Rev. Genet. 1976, 10, 31-51. [CrossRef]

102. Parker, J.S.; Palmer, R.W.; Whitehorn, M.A.F.; Edgar, L.A. Chiasma frequency effects of structural chromosome change. Chromosoma 1982, 85, 673-686. [CrossRef]

103. Chambers, S.R.; Hunter, N.; Louis, E.J.; Borts, R.H. The mismatch repair system reduces meiotic homeologous recombination and stimulates recombination-dependent chromosome loss. Mol. Cell. Biol. 1996, 16, 6110-6120. [CrossRef]

104. Liharska, T.; van Wordragen, M.; van Kammen, A.; Zabel, P.; Koornneef, M. Tomato chromosome 6: Effect of alien chromosomal segments on recombinant frequencies. Genome 1996, 39, 485-491. [CrossRef] [PubMed]

105. Chetelat, R.T.; Meglic, V.; Cisneros, P. A Genetic Map of Tomato Based on BC1 Lycopersicon esculentum $\times$ Solanum lycopersicoides Reveals Overall Synteny but Suppressed Recombination Between These Homeologous Genomes. Genetics 2000, 154, 857. [PubMed]

106. Opperman, R.; Emmanuel, E.; Levy, A.A. The Effect of Sequence Divergence on Recombination Between Direct Repeats in Arabidopsis. Genetics 2004, 168, 2207-2215. [CrossRef]

107. Li, L.; Jean, M.; Belzile, F. The impact of sequence divergence and DNA mismatch repair on homeologous recombination in Arabidopsis. Plant J. 2006, 45, 908-916. [CrossRef] [PubMed]

108. Lyon, M.T. A Genomic Genetic Map of the Common Sweet Orange and Poncirus Trifoliata. Ph.D. Thesis, University of California, Riverside, CA, USA, 2008.

109. Imai, A.; Yoshioka, T.; Hayashi, T. Quantitative trait locus (QTL) analysis of fruit-quality traits for mandarin breeding in Japan. Tree Genet. Genomes 2017, 13, 79. [CrossRef]

110. Guo, F.; Yu, H.; Tang, Z.; Jiang, X.; Wang, L.; Wang, X.; Xu, Q.; Deng, X. Construction of a SNP-based high-density genetic map for pummelo using RAD sequencing. Tree Genet. Genomes 2015, 11, 2. [CrossRef]

111. Ollitrault, P.; Navarro, L. Citrus. In Fruit Breeding; Badenes, M.L., Byrne, D.H., Eds.; Springer: Boston, MA, USA, 2012; pp. 623-662. ISBN 978-1-4419-0762-2.

Publisher's Note: MDPI stays neutral with regard to jurisdictional claims in published maps and institutional affiliations.

(C) 2020 by the authors. Licensee MDPI, Basel, Switzerland. This article is an open access article distributed under the terms and conditions of the Creative Commons Attribution (CC BY) license (http://creativecommons.org/licenses/by/4.0/). 